\title{
A Computer Program (ZONECONC) for Tabulating Concentration Statistics Using Results from the U.S. Geological Survey Modular Three-Dimensional Ground-Water Flow and Transport Model
}

Open-File Report 2005-1422 


\section{A Computer Program (ZONECONC) for Tabulating Concentration Statistics Using Results from the U.S. Geological Survey Modular Three-Dimensional Ground-Water Flow and Transport Model}

By Philip T. Harte

Open-File Report 2005-1422 


\section{U.S. Department of the Interior \\ Gale A. Norton, Secretary \\ U.S. Geological Survey \\ P. Patrick Leahy, Acting Director}

U.S. Geological Survey, Reston, Virginia: 2005

For product and ordering information:

World Wide Web: http://www.usgs.gov/pubprod

Telephone: 1-888-ASK-USGS

For more information on the USGS--the Federal source for science about the Earth, its natural and living resources, natural hazards, and the environment:

World Wide Web: http://www.usgs.gov

Telephone: 1-888-ASK-USGS

Any use of trade, product, or firm names is for descriptive purposes only and does not imply endorsement by the U.S. Government.

Although this report is in the public domain, permission must be secured from the individual copyright owners to reproduce any copyrighted materials contained within this report.

Suggested citation:

Harte, P.T., 2005, A computer program (ZONECONC) for tabulating concentration statistics using results from the U.S. Geological Survey modular three-dimensional ground-water flow and transport model: U.S. Geological Survey Open-File Report 2005-1422, 24 p. 


\section{Preface}

This report describes a computer program called ZONECONC that tabulates concentration data using results from the U.S. Geological Survey (USGS) Modular Three-Dimensional Ground-Water Flow and Solute Transport Model (MODFLOW-GWT). The program has been tested on a variety of model simulations, but it is possible that other applications could reveal errors. Users are requested to notify the USGS if errors are found in the program.

Although this program has been used by the USGS, no warranty, expressed or implied, is made by the USGS or the United States Government as to the accuracy and functioning of the program and related program material. Nor shall the fact of distribution constitute any such warranty, and no responsibility is assumed by the USGS in connection therewith.

The computer program is available through the World Wide Web at the address:

http://water.usgs.gov/software. 


\section{Acknowledgments}

This work was made possible by the U.S. Geological Survey, Office of Ground Water. The author appreciates the support and technical expertise of Arlen W. Harbaugh of the Office of Ground Water. The author also appreciates the help of Lenny F. Konikow and George Z. Hornberger of the U.S. Geological Survey, Eastern Region, Branch of Regional Research. Keith W. Robinson of the U.S. Geological Survey, New Hampshire-Vermont Water Science Center also contributed encouragement and support. A special thanks to Brian R. Mrazik for his leadership role at the U.S. Geological Survey, New Hampshire-Vermont Water Science Center. 


\section{Contents}

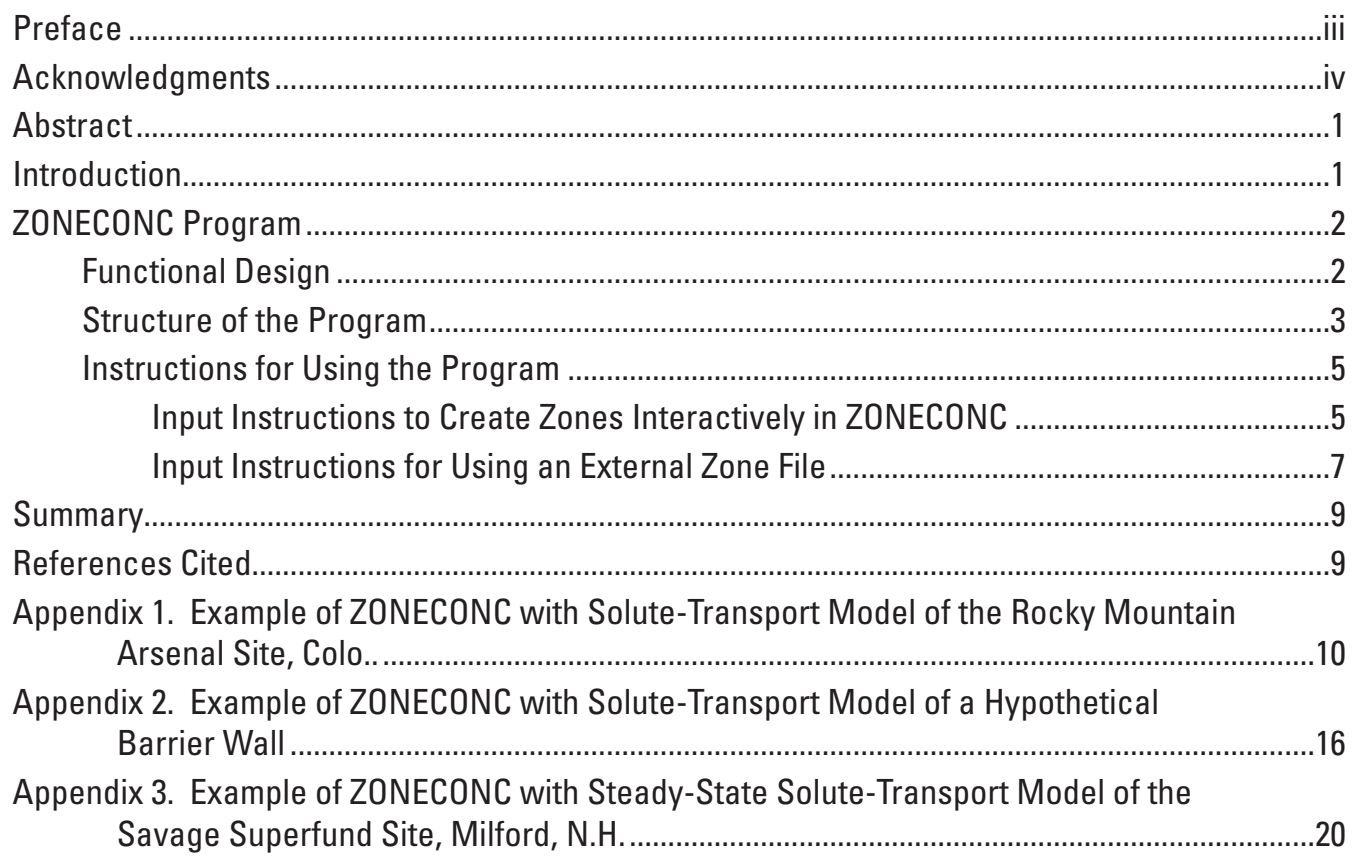

\section{Figures}

1. Example of the output file from ZONECONC ..........................................................................

2. Flowchart of routine for reading concentration data, tabulating statistics, and printing..........4

3. Example of a zone file used with the subroutine IZREAD of ZONECONC ................................. 


\title{
A Computer Program (ZONECONC) for Tabulating Concentration Statistics Using Results from the U.S. Geological Survey Modular Three-Dimensional Ground-Water Flow and Transport Model
}

By Philip T. Harte

\begin{abstract}
The computer program, called ZONECONC, tabulates concentration data using the results from the U.S. Geological Survey Modular Three-Dimensional Ground-Water Flow and Solute-Transport Model (MODFLOW-GWT). ZONECONC uses concentration data saved by MODFLOW-GWT in order to tabulate concentration-data statistics by zones of a ground-water-flow model. Zones are three-dimensional volumes of a flow model that are designated by zone numbers. The user assigns a zone number for each cell in the model either interactively by rectangular blocks or from an externally created zone file. ZONECONC allows for post processing of concentration data from MODFLOW-GWT in a quick and easy manner by tabulating zonal statistics to identify trends in concentrations. This report documents the design and use of ZONECONC; included are applications and three examples of the use of ZONECONC from a variety of MODFLOW-GWT model results.
\end{abstract}

\section{Introduction}

Tracking areal and temporal trends in chemical concentrations from solute-transport models is important for evaluating simulation results. Simple and efficient post-processing programs can facilitate this evaluation. A new computer program called ZONECONC was created by the U.S. Geological Survey (USGS) for this purpose.

ZONECONC, which is written in FORTRAN-95, tabulates zonal concentration statistics using results from the USGS Modular Three-Dimensional Ground-Water Flow and Solute Transport Model or MODFLOW-GWT (Harbaugh and others, 2000). Zones are defined in this report as three-dimensional volumes within a model. MODFLOW-GWT is a three-dimensional, finite-difference model code used to solve single species solute transport in ground-water flow. Post-processing programs, such as ZONECONC, help facilitate the analysis of modeled solute-transport results by assessing zone trends in modelcomputed concentrations. This concept of analyzing data by zones was patterned after the program ZONEBUDGET (Harbaugh, 1990), which calculates water budgets for zones of a flow model. ZONECONC tabulates concentration statistics by reading the concentration data produced from the ground-water transport (GWT) process of MODFLOW. The user can create zones in ZONECONC that will be used to tabulate concentration statistics or use an externally created file of zone information.

ZONECONC tracks zone information and concentration data in different ways. Zones are tracked based on a ground-waterflow model grid. Concentrations, however, are tracked based on a solute-transport subgrid (area of simulated transport within the model), which may be smaller than the flow-model grid. ZONECONC translates the concentration data onto the flow-model grid and tabulates statistics from the model grid and zones.

The purpose of this report is to document the design of ZONECONC and how to use the program. Three examples are provided that demonstrate the usefulness of ZONECONC to analyze concentration output from results of solute-transport models (appendixes 1,2, and 3). 


\section{ZONECONC Program}

A discussion of functional design, structure, and input instructions for ZONECONC is included to explain program use. Requirements and constraints to proper program execution are also included in the discussion.

\section{Functional Design}

The ASCII concentration-output file from MODFLOW-GWT is used in ZONECONC to create concentration statistics by area or zones. These ASCII (text only) concentration data are contained in a MODFLOW-GWT file called the CNCA file (Konikow and others, 1996, p. 71). The CNCA file outputs data per time and layer of the subgrid according to the output specified by the user in MODFLOW-GWT. Included in the CNCA output file is a header line that specifies the time and layer for the corresponding concentration data array. The header line is read by ZONECONC to identify the beginning of a concentration array. Between headers, the total number of concentration data in an array is a multiple of the subgrid rows and columns.

ZONECONC tabulates summary statistics on non-negative concentration values only. Therefore, inactive cells of a subgrid where solute transport is not calculated, as identified in the CNCA file by the CNOFLO term in MODFLOW-GWT (Konikow and others, 1996, p. 75), must be specified as a negative number. If a CNOFLO value such as -999.99 is used, inactive cells are easily identified. In some cases, a concentration value of an active cell becomes negative because of numerical computational issues in the solution of a solute-transport model. These cells need to be monitored by methods other then ZONECONC to identify problems with the solute-transport model.

MODFLOW-GWT allows for solute transport to be simulated on a subgrid, which can be a part of the flow-model grid or the entire model grid. ZONECONC uses zones based on the flow-model grid, similar to ZONEBUDGET. Concentration data are output from MODFLOW-GWT based on the subgrid. ZONECONC relates the zones based on the flow model to the concentration data, based on the subgrid, by reading information from two MODFLOW-GWT files-the discretization file that contains flow-model grid dimensions and the main input file for transport, called the GWT file, which contains subgrid dimensions.

Three types of GWT files can be used in MODFLOW-GWT. All three types can be read by ZONECONC to ascertain subgrid dimensions. The three types of GWT files, which differ based on solution options in MODFLOW-GWT, include (1) MOC, named after method of characteristics (Konikow and others, 1996, p. 71), (2) ELLAM, named after eulerian-lagrangian localized-adjoint method (Heberton and others, 2000), or (3) MOCIMP, named after implicit dispersive transport algorithm (Kipp and others, 1998). All three solution types designate line 3 of the GWT file to contain subgrid transport dimensions.

Zone data are created in ZONECONC using either a zone block approach or zone file approach. Zone numbers can range from 0 through 25 . The maximum number of zones can be increased by changing the program parameter NZDIM. It is not necessary to use all 25 zones, but a zone number must be assigned to each cell in the flow-model grid. Although 0 is a valid zone number, concentration statistics are not calculated for Zone 0 . Thus, the user can exclude cells from tabulation by assigning them to Zone 0 . Zone numbers should be labeled consecutively in ZONECONC to reduce extraneous output from ZONECONC. Zone block uses the subroutine BLOCK, whereas the zone file uses the subroutine IZREAD. Both subroutines were modified from the same subroutines in ZONEBUDGET.

The user must choose whether to use a zone file that contains zone information, which must be created externally of ZONECONC, or specify zones interactively in ZONECONC. The combination of both methods is not allowed. A zone file is a preexisting file that is read by ZONECONC. The option of creating zones interactively in a ZONECONC session allows for the creation of simple rectangular-shape zones or blocks. A block is a rectangular shape volume of cells defined by a range of layers, rows, and columns. For example, a block might be defined by layer 3, rows 7-20, and columns 2-26. A single zone value is assigned to all the cells in a block. If blocks overlap, the most recent zone assignment during an interactive session overrides any previous definitions. Blocks are useful for making quick zone assignments through an interactive session in ZONECONC. For either the zone file or the interactive approach, zone numbers must be consecutively numbered from 1 to 25 .

An example of tabulated concentration statistics from ZONECONC is shown in figure 1. For this example, zone information was created using the BLOCK option and only one block was designated for the entire layer 1. The output includes the concentration file (CNCA) name (bar3gg.cna) from MODFLOW-GWT, the output file name containing this information (r3gg51), zone information, and tabulated concentration data. The tabulated concentration data include the simulation time (in model units), zone number, the highest maximum (MAX.) concentration of any cell within that zone, the flow model row, column (COL.) and layer location of the maximum concentration cell, the minimum (MIN.) concentration for that zone, the mean concentration of the zone (only a true mean for uniform cells), total (cumulative) concentration (TOTAL), count (COUNT), which is the total number of non-negative (active) concentration cells in that zone, and the standard deviation (STAND.DEV.). The output also includes a count of cells with only positive concentration cells (PCOUNT), which can be used to track plume size. 


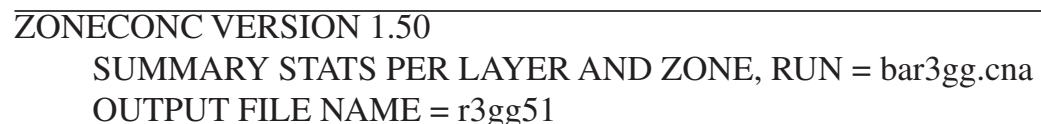

OUTPUT FILE NAME = r3gg51

Zone block: LAYERS 1-1 ROWS 1-19 COLUMNS 1-28 VALUE: 1

NUMBER OF ZONES: 1

READING CONCENTRATION DATA

STATISTICS ARE CALCULATED ON NON-NEGATIVE (VALUES $=>0$ ) CONCENTRATION EXCEPT PCOUNT (VALUES $>0$ )

\begin{tabular}{lclrccllllrl} 
TIME & ZONE & MAX. & ROW & COL. & LAYER & MIN. & MEAN & TOTAL & COUNT & PCOUNT & STAND. DEV. \\
0.00000 & 1 & $0.1000 \mathrm{E}+06$ & 13 & 15 & 1 & $0.0000 \mathrm{E}+00$ & $0.4135 \mathrm{E}+04$ & $0.2200 \mathrm{E}+07$ & 532 & 22 & $0.1988 \mathrm{E}+05$ \\
3652.50 & 1 & $0.1000 \mathrm{E}+06$ & 13 & 13 & 1 & $0.6430 \mathrm{E}-04$ & $0.4134 \mathrm{E}+04$ & $0.2199 \mathrm{E}+07$ & 532 & 532 & $0.1984 \mathrm{E}+05$ \\
\hline
\end{tabular}

Figure 1. Example of the output file from ZONECONC.

The TOTAL concentration term can be used to track an approximate mass of solute if the grid-cell size, thickness, and porosity (essentially volume of the model) is uniform between cells and zones of a model. For variable grid-cell sizes, the TOTAL term is less useful for tracking mass because mass would be affected by the spatial variations in the volume of each cell and zone.

To facilitate the analysis of output from ZONECONC, the output file (fig. 1) can be edited with any ASCII file editor to allow ZONECONC statistical tabulations to be used by any graphics software program. ZONECONC output from a large CNCA file, with results from multiple time series, benefits from graphical processing because trends in zone concentrations with time may be more easily identifiable in graphs than tables. For the simple example in figure 1, only two time periods were output to the CNCA file, therefore, only two periods were output in ZONECONC and are easily discernible in a table format.

ZONECONC creates a second output file, called the "check output file," that can be used to ensure the CNCA file is correctly read by ZONECONC. A brief explanation of this type of file is provided in the following paragraphs. A detailed explanation of the contents of this output file is provided in appendixes 1-3.

The "check file" prints information related to the interactive ZONECONC session, specified zones, and milestones in the reading and tabulation of concentration data from the CNCA file. The "check file" is most useful in verifying that ZONECONC correctly reads the CNCA file by reprinting the last row of concentration data from each time period of the CNCA file. These data can be compared to the input CNCA file to ensure that ZONECONC was properly executed.

\section{Structure of the Program}

The ZONECONC program consists of four parts-a main (MAIN) program and three subroutines (IZREAD, BLOCK, and RARRAY). The MAIN program controls overall program flow and includes an input section. Various computer-file unit numbers are used by the program to interchange input and output during the execution of ZONECONC and are defined at the beginning of the MAIN program. Computer file units are designated by six variable names within ZONECONC (IOUT, INZN1, INZN2, INZN3, INZN4, and INZN5). A PARAMETER statement NODDIM specifies maximum array size, which can be increased, if needed. NODDIM must be larger than the total number of cells calculated from the product of the number of flow-model layers, rows, and columns in the flow-model grid. The COMMENT statements in FORTRAN help explain parameter functions throughout the program.

Two subroutines deal with zone input, and follow procedures defined in ZONEBUDGET (Harbaugh, 1990). Subroutine IZREAD reads zones from a zone file, one value for each cell in the model grid. The values are read by layer. The data for each layer are preceded by a control record line similar to the one used by MODFLOW (McDonald and Harbaugh, 1988, p. 14-4) that specifies unit number and format of the zone file. Subroutine IZREAD can be skipped in favor of subroutine BLOCK if no external zone file is available. In contrast, subroutine BLOCK prompts the user to define zones interactively but can be skipped if an external zone file is available and read by ZONECONC.

Reading of concentration data from the CNCA file, tabulation of concentration statistics, and printing are done in the subroutine RARRAY. Reading of concentration data is controlled by the header line that is printed in the CNCA file. After the header line is read (fig. 2), reading of concentration data occurs per time, layer, and array (row and column), respectively. The maximum number of layers, rows, and columns is controlled by the subgrid dimensions specified in the GWT file of MODFLOW-GWT. 


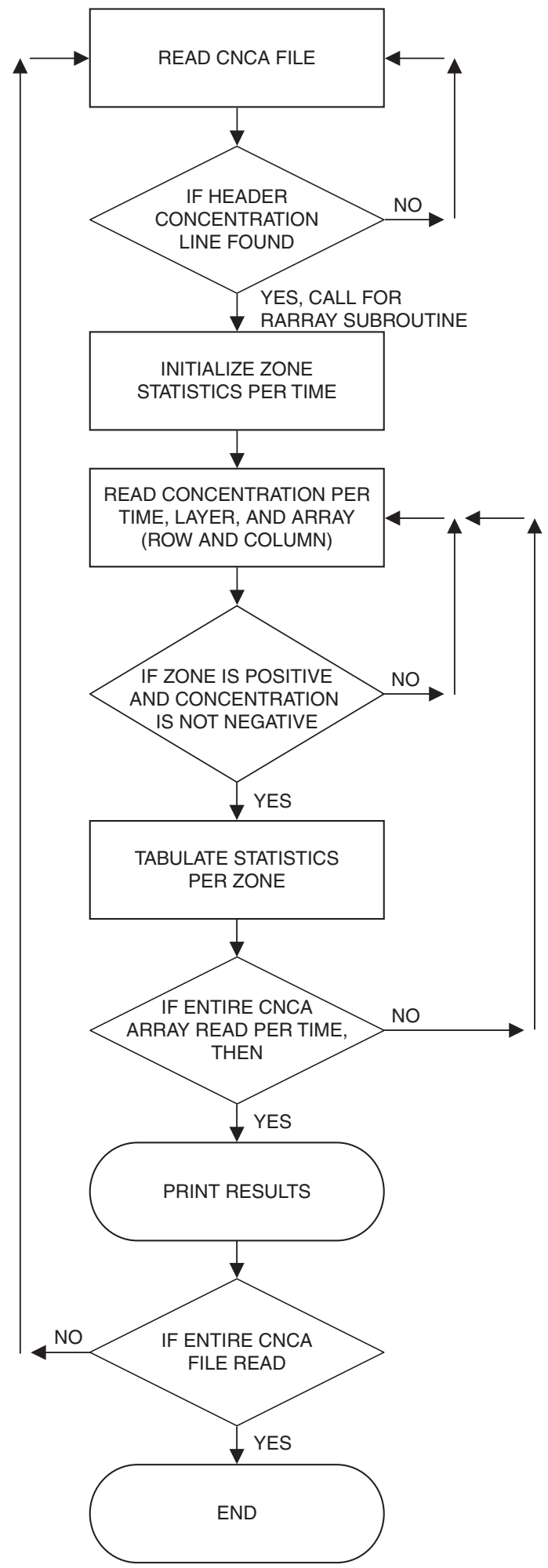

Figure 2. Flowchart of routine for reading concentration data, tabulating statistics, and printing. 


\section{Instructions for Using the Program}

Concentration data from MODFLOW-GWT must be saved in a file prior to executing ZONECONC. This file saving is accomplished in the MODFLOW-GWT program in data set 8 of the GWT file (Konikow and others, 1996, p. 74; Heberton and others, 2000, p. 49; Kipp and others, 1998, p. 39). The MODFLOW-GWT variable NPNTCL controls the amount of concentration-data output to the CNCA file. ZONECONC will print tabulated concentration data for all zones at all the times for which MODFLOW-GWT has saved concentration data. The CNOFLO value (data set 9) of the GWT file must be specified as negative so that ZONECONC will ignore all inactive solute-transport cells. If a large negative CNOFLO value (example, -999.99) is used, inactive transport cells are easily identifiable.

After concentration data have been saved, ZONECONC can be executed; however, the user must also prepare a zone file if it is desired to read zone information from a file. Zone information from an external zone file allows for complex zone assignment of cells in irregular (non-rectangular) patterns within the flow-model grid. The instructions for preparing a zone file are contained in the section "Input Instructions for Using an External Zone File." Alternatively, zones can be defined in rectangular "block" shapes through the interactive zone session in ZONECONC.

When ZONECONC is executed, the user will be prompted for information. The program will also display information showing its progress. The following is a list of the prompts and a description of how to respond.

PROMPT 1: "Enter input CNCA file name:"

This prompt is the CNCA file in which the concentration data have been saved in MODFLOW-GWT. ZONECONC accommodates file names that are up to 24 characters long.

PROMPT 2: "Enter the output file name 1:"

This prompt is a new file that will hold the output (main output file) of the tabulated concentration results from

ZONECONC. See figure 1 for example of output.

PROMPT 3: "Enter INPUT GWT file name:"

This prompt is the main GWT file from MODFLOW-GWT that contains the solute-transport-model-subgrid dimensions.

PROMPT 4: "INPUT discretization file name:"

This prompt is the discretization file (Harbaugh and others, 2000) from MODFLOW-GWT that contains the flow-modelgrid dimensions.

PROMPT 5: "Enter OUTPUT FILE TO WRITE CONC. ARRAY:"

This prompt is an additional output file, called the "check file," that can be used for verification of ZONECONC output. See appendix 1, section 3 for example of contents.

PROMPT 6: "Enter the name of your ZONE INPUT FILE (CR for interactive):"

If you want to read zone data from a zone file, enter the name of the file here. If a non-existent file is named, the prompt will be reissued. If a blank line is entered, a prompt will be displayed to enter zones interactively by blocks.

To demonstrate ZONECONC, three sample problems are provided in appendixes 1-3. The sample problems are of three different transport models with different complexities and sizes. The examples include two relatively small (less than 10,000 model cells) models and one large (165,375 model cells) model. Different options for entering zone data are also used.

\section{Input Instructions to Create Zones Interactively in ZONECONC}

This section describes the procedure for using the internal interactive session of ZONECONC to create rectangular zones or blocks. An example is provided in this section of a relatively small model grid (3 layers with 15 rows and columns), but the procedure is the same for any size grid.

The interactive-session prompt asks for a range of layers, rows, and columns to be given a specified zone number. Before input is started, all cells in the grid are assigned to Zone 0 . The maximum number of zones that can be entered is 25 . A range of layers from 0 through 0 ends the interactive input of zones. The format for entering numbers is free format; numbers may be placed anywhere on a line with a comma or one or more blanks separating adjacent values such as 1,1 or 1,2. A blank cannot be used for the number 0 . An example of a session in which zones are defined interactively is described below. 
ZONECONC version 1.50

PROMPT 1: "Enter the name of your ZONE INPUT FILE (CR for interactive):"

(enter carriage return here)

PROMPT 2: "Enter the start layer, stop layer (0,0 means done):"

1,1

PROMPT 3: "Enter the start row, stop row:"

1,15

PROMPT 4: "Enter the start column, stop column:"

1,15

PROMPT 5: "Enter the zone for this block:"

1

PROMPT 6: "Enter the start layer, stop layer ( 0,0 means done):"

2,2

PROMPT 7: "Enter the start row, stop row:"

1,15

PROMPT 8: "Enter the start column, stop column:"

1,15

PROMPT 9: "Enter the zone for this block:"

2

PROMPT 10: "Enter the start layer, stop layer ( 0,0 means done):"

3,3

PROMPT 11: "Enter the start row, stop row:"

1,15

PROMPT 12: "Enter the start column, stop column:"

1,15

PROMPT 13: "Enter the zone for this block:"

3

PROMPT 14: "Enter the start layer, stop layer ( 0,0 means done):"

1,2

PROMPT 15: "Enter the start row, stop row:"

1,15

PROMPT 16: "Enter the start column, stop column:"

1,1

PROMPT 17: "Enter the zone for this block:"

4

PROMPT 18: "Enter the start layer, stop layer ( 0,0 means done):"

0,0

4 is your highest zone (Program displays highest numbered zone)

The above interactive session creates a single zone per layer, numbered 1,2, and 3 for layer 1,2, and 3, respectively. The session creates a separate zone 4 for the first column of layers 1 and 2, which would be useful in tracking concentrations at a model boundary. 


\section{Input Instructions for Using an External Zone File}

This section describes the procedure for using an external zone file. Zone information from an ASCII file created externally of ZONECONC can be used to identify model zones. The format for these external zone files is discussed and can be created in a standard text editor program. ZONECONC reads the external zone file in a ZONECONC session after the user provides the name of the zone file.

The zone file contains records (specified on separate lines of the zone file) that define the conditions to read a zone number for each model cell. Up to four Record Types can be included in the file. Some combination of Record Types are never used simultaneously because of programming constraints and these constraints are described in the Record-Type discussion of this report. Only positive zone numbers are used in the zone file.

Each Record Type contains one or more input items entered in either fixed or free format. For fixed format, the input data values must be in a specific range of columns, called a field. In the example shown in figure 3, the field width is 6 . Numeric values are right justified in the field; character values are left justified. A blank represents a 0 in a fixed-format numeric field. For free format, there are no absolute field sizes. Items are separated by one or more spaces or by a comma plus optional spaces. Because a space is a delimiter that can separate values, a space cannot be used to indicate 0 in free format.

Items to be input are given symbolic item names. Each item name, such as LOCAT and ICONST, is the name of a program variable or array. When an item is an array (often called a table or matrix), the dimensions of the array are included as part of the item name. For example, IZONE (NCOL,NROW) is a matrix of zone numbers with NROW rows and NCOL columns in each row. For each item, the required format is specified by ZONECONC. "Free" indicates free format. "I $x$ " indicates fixed-format integer values, where $x$ is the width of the field or number of spaces. " $n \mathbf{I} x$ " indicates multiple integer fields, where $n$ is the number of fields. "A $x$ " indicates fixed-format character values, where $x$ is the field width.

An example of a zone file is shown in figure 3. The layer, row, and column dimensions of the grid are specified in line 1 (Record Type 1). Line 2 (Record Type 2) specifies the location (LOCAT) of the zone file (INTERNAL), and the format (FMTIN) of the zone array (28I6).

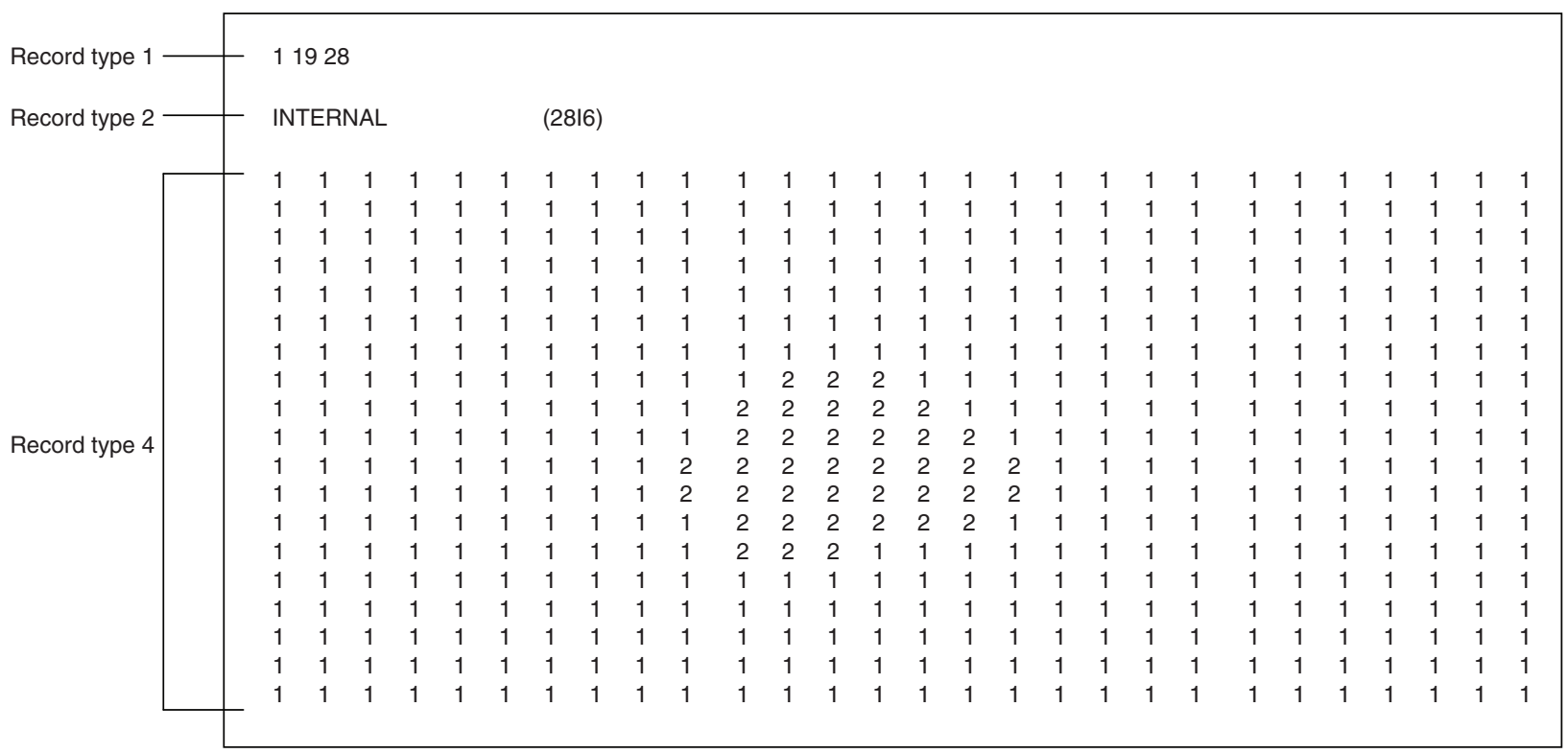

Figure 3. Example of a zone file used with the subroutine IZREAD of ZONECONC. 
The following is a description of the four Record Types as defined by Harbaugh (1990), in the order read by ZONECONC.

Item: NLAY NROW NCOL

\section{Record Type 1}

Format: Free Free Free

Explanation:

NLAY is the number of layers in the model grid. NROW is the number of rows, and NCOL is the number of columns.

Note: Record Types 2-4 define zone values for one layer of the model grid. Record Types 2-4 must be repeated for each layer in the model grid. Layers are input in order starting with layer 1.

\section{Record Type 2}

Item: LOCAT ICONST FMTIN IPRN

Format A10 I10 A20 I10

Explanation:

LOCAT indicates the source or location of the zone data for the layer.

A LOCAT value of "CONSTANT" indicates that all cells in the layer have the same zone value, which is the value of item ICONST. In this case, there will be no Record Types 3 and 4.

A LOCAT value of "INTERNAL" indicates that the zone data for the layer are contained within the zone file. In figure 3, there will be no Record Type 3, so Record Type 4 follows Record Type 2.

A LOCAT value of "EXTERNAL" indicates that the zone data for the layer are contained in a file other than the zone file. The name of this file is entered in Record Type 3.

ICONST is the zone value that is assigned to each cell in the layer if LOCAT has the value "CONSTANT." If LOCAT is other than "CONSTANT," then ICONST is not used. The zone value must be greater than or equal to 0 and less than or equal to 25. (This maximum value can be changed by entering a new number for program parameter NZDIM.)

FMTIN is the FORTRAN format of the data in Record Type 4. If LOCAT has the value "CONSTANT," then FMTIN is not used. FMTIN must be in a standard FORTRAN format specification for reading integer data. The format must include parentheses. For example, "20I4" indicates that 20 integers will be read from each record, and each integer occupies a field of 4 spaces or columns. If the FMTIN value is blank, free format is used.

IPRN determines if Record Type 4 values are printed in the main output file. If IPRN is greater than or equal to 0 or null, the values are printed. If IPRN is less than 0 , values are not printed. If LOCAT has the value "CONSTANT," then IPRN is not used.

Item: NAME

\section{Record Type 3}

Format A80

Explanation:

NAME is the name of another external file that contains zone numbers for a layer of the flow model. Include Record Type 3 only if LOCAT has the value "EXTERNAL."

Item: IZONE(NCOL,NROW)

\section{Record Type 4}

Format: Defined by Record Type 2

Explanation:

IZONE contains the zone values for each cell in a layer. IZONE is read only if LOCAT (Record Type 1) has the value "EXTERNAL" or "INTERNAL." If the location is "INTERNAL," then the zone numbers are contained in this zone file. If the location is "EXTERNAL," then the zone numbers are contained in the file that is named by the item NAME (Record Type 3). The format of the data is defined by FMTIN. Data are read a row at a time starting with row 1. If a row of the data contains more values than one record (line) holds, then additional records (lines) will be read using the same format until all values for one row have been read. Each row of data must start as a new record. The zone values must be greater than or equal to 0 and less than or equal to 25 . 


\section{Summary}

The computer program, called ZONECONC, which is written in FORTRAN-95, was created to analyze concentration data output from the U.S. Geological Survey (USGS) Modular Three-Dimensional Ground-Water Flow and Solute Transport Model (MODFLOW-GWT). ZONECONC uses concentration data saved by MODFLOW-GWT in order to tabulate concentration data statistics by zones (volumes) within a model. Zones can span multiple layers of a model and are designated by zone numbers. The user assigns a zone number for each cell in the model either interactively by blocks (rectangular shapes) or from an external zone file (rectangular or non-rectangular shapes). Zone definitions follow procedures based on the USGS computer program ZONEBUDGET.

Three examples are provided to demonstrate how ZONECONC is used to tabulate zone statistics from MODFLOW-GWT concentration data. The examples show that ZONECONC is a simple and efficient program to use to identify areal (by zones) and temporal trends in chemical concentrations from solute-transport models.

\section{References Cited}

Harbaugh, A.W., 1990, A computer program for calculating subregional water budgets using results from the U.S. Geological Survey modular three-dimensional finite-difference ground-water model: U.S. Geological Survey Open-File Report 90-392, $24 \mathrm{p}$.

Harbaugh, A.W., Banta, E.R., Hill, M.C., and McDonald, M.G., 2000, MODFLOW-2000, The U.S. Geological Survey modular ground-water model-User guide to modularization concepts and the ground-water flow process: U.S. Geological Survey Open-File Report 00-92, 121 p.

Harte, P.T., 2004, Simulation of solute transport of tetrachloroethylene in ground water of the glacial-drift aquifer at the Savage Municipal Well Superfund site, Milford, New Hampshire, 1960-2000, U.S. Geological Survey Scientific Investigations Report 2004-5176, 84 p.

Heberton, C.I., Russell, T.F., Konikow, L.F., and Hornberger, G.Z., 2000, A three-dimensional finite-volume eulerian-lagrangian localized adjoint method (ellam) for solute transport modeling: U.S. Geological Survey Water-Resources Investigations Report 00-4087, 63 p.

Kipp, K.L., Jr., Konikow, L.F., and Hornberger, G.Z., 1998, An implicit dispersive transport algorithm for the U.S. Geological Survey MOC3D solute-transport model: U.S. Geological Survey Water-Resources Investigations Report 98-4234, 54 p.

Konikow, L.F., 1977, Modeling chloride movement in the alluvial aquifer at the Rocky Mountain Arsenal, Colorado: U.S. Geological Survey Water-Supply Paper Report 2004, 43 p.

Konikow, L.F., Goode, D.J., and Hornberger, G.Z., 1996, A three-dimensional method of characteristics solute-transport model (MOC3D): U.S. Geological Survey Water-Resources Investigations Report 96-4267, 87 p.

McDonald, M.G., and Harbaugh, A.W., 1988, A modular three-dimensional finite-difference ground-water flow model: U.S. Geological Survey Techniques of Water-Resources Investigations, book 6, chap. A1, 586 p. 


\section{APPENDIX 1. Example of ZONECONC with Solute-Transport Model of the Rocky Mountain Arsenal Site, Colo.}

A simulation based on the Rocky Mountain Arsenal solute-transport model (Konikow, 1977) was analyzed using ZONECONC version 1.5. One ZONECONC test was run. The option to interactively create zones in the model with ZONECONC following the subroutine IZONE was used in the test (Harbaugh, 1990).

The Rocky Mountain Arsenal model consists of one model layer (fig. 1-1). The grid and transport subgrid are the same dimensions. The initial starting conditions are for an uncontaminated aquifer with no solute. The input of chloride, a conservative solute, is simulated over time under steady-state flow conditions. A detailed description of the transport conditions is described by Konikow (1977).

\section{References Cited}

Harbaugh, A.W., 1990, A computer program for calculating subregional water budgets using results from the U.S. Geological Survey modular three-dimensional finite-difference ground-water model: U.S. Geological Survey Open-File Report 90-392, $24 \mathrm{p}$.

Konikow, L.F., 1977, Modeling chloride movement in the alluvial aquifer at the Rocky Mountain Arsenal, Colorado: U.S. Geological Survey Water-Supply Paper 2004, 43 p.

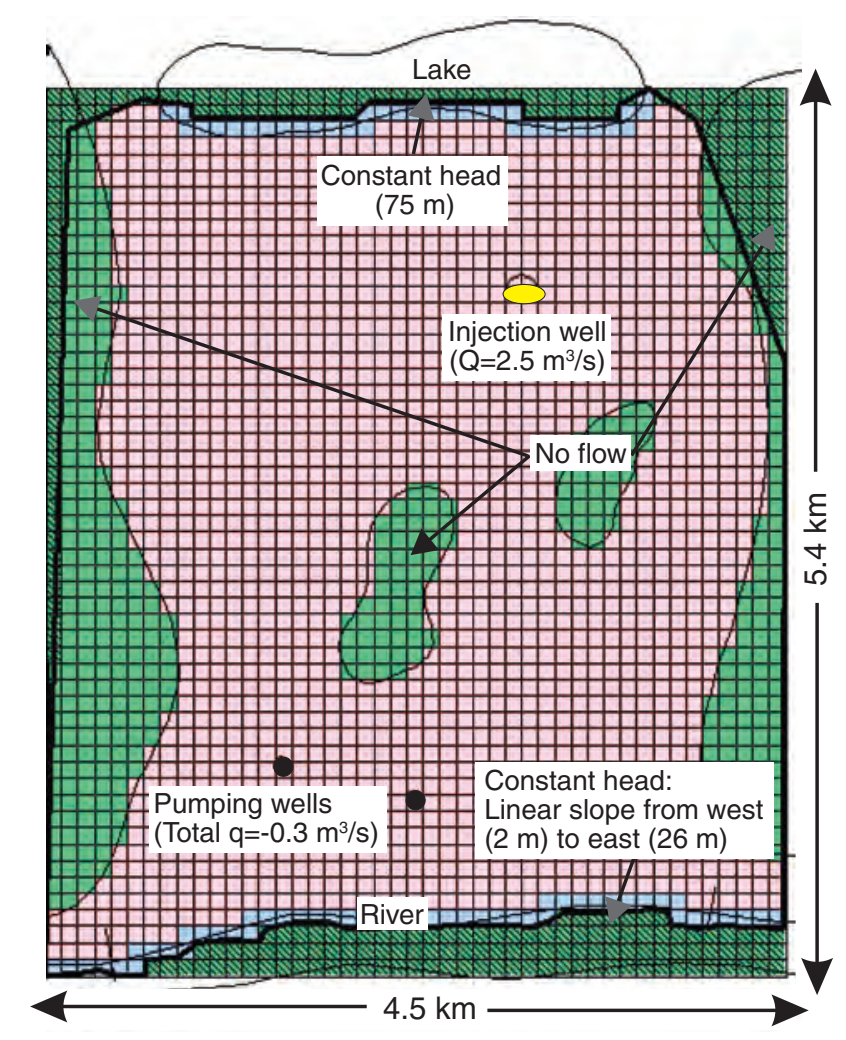

Figure 1-1. Finite-difference grid and boundary conditions of a solute-transport model of the Rocky Mountain Arsenal site, Colo. [ $\mathrm{km}=$ kilometers; $\mathrm{m}=$ meters; $\mathrm{s}=$ seconds] 


\section{Example test run: Interactive (user-defined) designation of zone values for the model.}

1. Input instructions follow (Unbolded font is program prompts and output, bold is user typed response, red is author commentary (not provided in program).

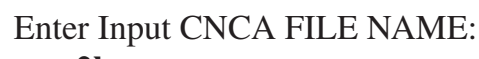


2. Output from the main output file.

ZONECONC VERSION 1.50

SUMMARY STATS PER LAYER AND ZONE, RUN = rma2k.cna

OUTPUT FILE NAME $=$ rocky 29

Zone block: LAYERS 1- 1 ROWS 1-54 COLUMNS 1-45 VALUE: 1

NUMBER OF ZONES: 1

READING CONCENTRATION DATA

\begin{tabular}{|c|c|c|c|c|c|c|c|c|c|c|c|}
\hline TIME & ZONE & MAX. & ROW & COL. & LAYER & MIN. & MEAN & TOTAL & COUNT & PCOUNT & STAND. DEV. \\
\hline 0.00000 & 1 & $0.0000 \mathrm{E}+00$ & 54 & 6 & 1 & $0.0000 \mathrm{E}+00$ & $0.0000 \mathrm{E}+00$ & $0.0000 \mathrm{E}+00$ & 1791 & 0 & $0.0000 \mathrm{E}+00$ \\
\hline $0.105190 \mathrm{E}+07$ & 1 & $0.5314 \mathrm{E}+03$ & 13 & 29 & 1 & $0.4089 \mathrm{E}-41$ & $0.1315 \mathrm{E}+01$ & $0.1177 \mathrm{E}+04$ & 895 & 895 & $0.2501 \mathrm{E}+02$ \\
\hline 0.21038 & 1 & 0.881 & 13 & 29 & 1 & -35 & 0.25 & $0.2315 \mathrm{E}+04$ & 899 & 899 & $\mathrm{E}+02$ \\
\hline $0.315580 \mathrm{E}+07$ & 1 & $0.1101 \mathrm{E}+04$ & 13 & 29 & 1 & $0.1735 \mathrm{E}-33$ & $0.3739 \mathrm{E}+01$ & $0.3496 \mathrm{E}+04$ & 935 & 935 & $0.5386 \mathrm{E}+02$ \\
\hline $0.420770 \mathrm{E}+07$ & 1 & $0.1229 \mathrm{E}+04$ & 13 & 29 & 1 & $0.8433 \mathrm{E}-34$ & $0.5132 \mathrm{E}+01$ & $0.4645 \mathrm{E}+04$ & 905 & 905 & $0.6490 \mathrm{E}+02$ \\
\hline $0.525960 \mathrm{E}+07$ & 1 & $0.1293 \mathrm{E}+04$ & 13 & 29 & 1 & $0.3144 \mathrm{E}-31$ & $0.6203 \mathrm{E}+01$ & $0.5732 \mathrm{E}+04$ & 924 & 924 & $0.7283 \mathrm{E}+02$ \\
\hline $0.631150 \mathrm{E}+07$ & 1 & $0.1314 \mathrm{E}+04$ & 13 & 29 & 1 & $0.1027 \mathrm{E}-32$ & $0.7442 \mathrm{E}+01$ & $0.6817 \mathrm{E}+04$ & 916 & 916 & $0.8082 \mathrm{E}+02$ \\
\hline
\end{tabular}

The output includes the time (in model units), zone identifier, maximum concentration, location in the flow model grid row and column and layer of the maximum location, minimum concentration, mean concentration of zone (only a true mean for uniform cells), total (cumulative) concentration (a pseudo mass value), and count, which is the total number of non-negative (active) concentration cells in that zone. The output also includes a count of cells with positive concentration cells only (PCOUNT) that can be used to track plume size and the standard deviation.

Examination of this ZONECONC output result shows that the maximum concentration found at a cell in the zone and the total concentration increases with time and peaks at time $=0.6312 \mathrm{E}+7$. The maximum concentration location occurs at row 13 and column 29. The initial time shows 1,791 cells are zero (no positive cells). PCOUNT increases to time $=0.3156 \mathrm{E}+7$ and oscillates afterwards indicating the plume size reaches a static distribution.

\section{Output example from the "check output" file.}

CHECK FILE FOR: rocky29

CONCENTRATIONS $\quad$ LAYER $=1 \quad$ SLAYER $=1 \quad$ TIME $=0.00000000 \mathrm{E}+00$

Print of concentration header for specified time. LAYER equals flow model-grid layer and SLAYER equals subgrid layer.

$\mathrm{MNCOL}=45 \quad \mathrm{MNROW}=54$

MNCOL equals to the number of subgrid columns and MNROW equals to number of subgrid rows.

$\begin{array}{rrrrrrr}0.000 & 0.000 & 0.000 & 0.000 & 0.000 & 0.000 & -999.9 \\ -999.9 & -999.9 & -999.9 & -999.9 & -999.9 & -999.9 & -999.9 \\ -999.9 & -999.9 & -999.9 & -999.9 & -999.9 & -999.9 & -999.9 \\ -999.9 & -999.9 & -999.9 & -999.9 & -999.9 & -999.9 & -999.9 \\ -999.9 & -999.9 & -999.9 & -999.9 & -999.9 & -999.9 & -999.9 \\ -999.9 & -999.9 & -999.9 & -999.9 & -999.9 & -999.9 & -999.9 \\ -999.9 & -999.9 & -999.9 & & & & \end{array}$

Check file prints out location and data for last row and column of subgrid for the specified time period.

PRINT STATS FOR = 54544545 zone 1

Print display indicates statistical summary information is being sent to main output file for that zone for each time period.

The number of rows (model and subgrid) and number of columns (model and subgrid) are printed. 
ZONES OF MODEL GRID

IZONE LAYER $=1$

$\begin{array}{llllllllllllllllllllllllllllllllllllllllllllll}1 & 1 & 1 & 1 & 1 & 1 & 1 & 1 & 1 & 1 & 1 & 1 & 1 & 1 & 1 & 1 & 1 & 1 & 1 & 1 & 1 & 1 & 1 & 1 & 1 & 1 & 1 & 1 & 1 & 1 & 1 & 1 & 1 & 1 & 1 & 1 & 1 & 1 & 1 & 1 & 1 & 1 & 1 & 1 & 1\end{array}$ $\begin{array}{llllllllllllllllllllllllllllllllllllllllllllllllllllll}1 & 1 & 1 & 1 & 1 & 1 & 1 & 1 & 1 & 1 & 1 & 1 & 1 & 1 & 1 & 1 & 1 & 1 & 1 & 1 & 1 & 1 & 1 & 1 & 1 & 1 & 1 & 1 & 1 & 1 & 1 & 1 & 1 & 1 & 1 & 1 & 1 & 1 & 1 & 1 & 1 & 1 & 1 & 1 & 1\end{array}$ $\begin{array}{llllllllllllllllllllllllllllllllllllllllllllll}1 & 1 & 1 & 1 & 1 & 1 & 1 & 1 & 1 & 1 & 1 & 1 & 1 & 1 & 1 & 1 & 1 & 1 & 1 & 1 & 1 & 1 & 1 & 1 & 1 & 1 & 1 & 1 & 1 & 1 & 1 & 1 & 1 & 1 & 1 & 1 & 1 & 1 & 1 & 1 & 1 & 1 & 1 & 1 & 1\end{array}$ $\begin{array}{lllllllllllllllllllllllllllllllllllllllllllllllllll}1 & 1 & 1 & 1 & 1 & 1 & 1 & 1 & 1 & 1 & 1 & 1 & 1 & 1 & 1 & 1 & 1 & 1 & 1 & 1 & 1 & 1 & 1 & 1 & 1 & 1 & 1 & 1 & 1 & 1 & 1 & 1 & 1 & 1 & 1 & 1 & 1 & 1 & 1 & 1 & 1 & 1 & 1 & 1 & 1\end{array}$ $\begin{array}{llllllllllllllllllllllllllllllllllllllllllllllllll}1 & 1 & 1 & 1 & 1 & 1 & 1 & 1 & 1 & 1 & 1 & 1 & 1 & 1 & 1 & 1 & 1 & 1 & 1 & 1 & 1 & 1 & 1 & 1 & 1 & 1 & 1 & 1 & 1 & 1 & 1 & 1 & 1 & 1 & 1 & 1 & 1 & 1 & 1 & 1 & 1 & 1 & 1 & 1 & 1\end{array}$ $\begin{array}{llllllllllllllllllllllllllllllllllllllllllllll}1 & 1 & 1 & 1 & 1 & 1 & 1 & 1 & 1 & 1 & 1 & 1 & 1 & 1 & 1 & 1 & 1 & 1 & 1 & 1 & 1 & 1 & 1 & 1 & 1 & 1 & 1 & 1 & 1 & 1 & 1 & 1 & 1 & 1 & 1 & 1 & 1 & 1 & 1 & 1 & 1 & 1 & 1 & 1 & 1\end{array}$

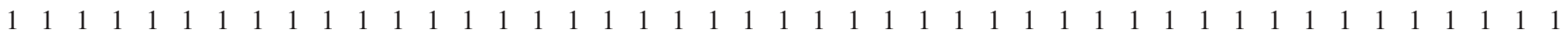
$\begin{array}{lllllllllllllllllllllllllllllllllllllllllllllllllll}1 & 1 & 1 & 1 & 1 & 1 & 1 & 1 & 1 & 1 & 1 & 1 & 1 & 1 & 1 & 1 & 1 & 1 & 1 & 1 & 1 & 1 & 1 & 1 & 1 & 1 & 1 & 1 & 1 & 1 & 1 & 1 & 1 & 1 & 1 & 1 & 1 & 1 & 1 & 1 & 1 & 1 & 1 & 1 & 1\end{array}$ $\begin{array}{lllllllllllllllllllllllllllllllllllllllllllllllllll}1 & 1 & 1 & 1 & 1 & 1 & 1 & 1 & 1 & 1 & 1 & 1 & 1 & 1 & 1 & 1 & 1 & 1 & 1 & 1 & 1 & 1 & 1 & 1 & 1 & 1 & 1 & 1 & 1 & 1 & 1 & 1 & 1 & 1 & 1 & 1 & 1 & 1 & 1 & 1 & 1 & 1 & 1 & 1 & 1\end{array}$ $\begin{array}{lllllllllllllllllllllllllllllllllllllllllllllllllllllll}1 & 1 & 1 & 1 & 1 & 1 & 1 & 1 & 1 & 1 & 1 & 1 & 1 & 1 & 1 & 1 & 1 & 1 & 1 & 1 & 1 & 1 & 1 & 1 & 1 & 1 & 1 & 1 & 1 & 1 & 1 & 1 & 1 & 1 & 1 & 1 & 1 & 1 & 1 & 1 & 1 & 1 & 1 & 1 & 1\end{array}$ $\begin{array}{llllllllllllllllllllllllllllllllllllllllllllllllll}1 & 1 & 1 & 1 & 1 & 1 & 1 & 1 & 1 & 1 & 1 & 1 & 1 & 1 & 1 & 1 & 1 & 1 & 1 & 1 & 1 & 1 & 1 & 1 & 1 & 1 & 1 & 1 & 1 & 1 & 1 & 1 & 1 & 1 & 1 & 1 & 1 & 1 & 1 & 1 & 1 & 1 & 1 & 1 & 1\end{array}$ $\begin{array}{lllllllllllllllllllllllllllllllllllllllllllllllllll}1 & 1 & 1 & 1 & 1 & 1 & 1 & 1 & 1 & 1 & 1 & 1 & 1 & 1 & 1 & 1 & 1 & 1 & 1 & 1 & 1 & 1 & 1 & 1 & 1 & 1 & 1 & 1 & 1 & 1 & 1 & 1 & 1 & 1 & 1 & 1 & 1 & 1 & 1 & 1 & 1 & 1 & 1 & 1 & 1\end{array}$ $\begin{array}{llllllllllllllllllllllllllllllllllllllllllllllllllllllll}1 & 1 & 1 & 1 & 1 & 1 & 1 & 1 & 1 & 1 & 1 & 1 & 1 & 1 & 1 & 1 & 1 & 1 & 1 & 1 & 1 & 1 & 1 & 1 & 1 & 1 & 1 & 1 & 1 & 1 & 1 & 1 & 1 & 1 & 1 & 1 & 1 & 1 & 1 & 1 & 1 & 1 & 1 & 1 & 1\end{array}$ $\begin{array}{lllllllllllllllllllllllllllllllllllllllllllllllllllll}1 & 1 & 1 & 1 & 1 & 1 & 1 & 1 & 1 & 1 & 1 & 1 & 1 & 1 & 1 & 1 & 1 & 1 & 1 & 1 & 1 & 1 & 1 & 1 & 1 & 1 & 1 & 1 & 1 & 1 & 1 & 1 & 1 & 1 & 1 & 1 & 1 & 1 & 1 & 1 & 1 & 1 & 1 & 1 & 1\end{array}$ $\begin{array}{llllllllllllllllllllllllllllllllllllllllllllllllll}1 & 1 & 1 & 1 & 1 & 1 & 1 & 1 & 1 & 1 & 1 & 1 & 1 & 1 & 1 & 1 & 1 & 1 & 1 & 1 & 1 & 1 & 1 & 1 & 1 & 1 & 1 & 1 & 1 & 1 & 1 & 1 & 1 & 1 & 1 & 1 & 1 & 1 & 1 & 1 & 1 & 1 & 1 & 1 & 1\end{array}$ $\begin{array}{lllllllllllllllllllllllllllllllllllllllllllllllllllll}1 & 1 & 1 & 1 & 1 & 1 & 1 & 1 & 1 & 1 & 1 & 1 & 1 & 1 & 1 & 1 & 1 & 1 & 1 & 1 & 1 & 1 & 1 & 1 & 1 & 1 & 1 & 1 & 1 & 1 & 1 & 1 & 1 & 1 & 1 & 1 & 1 & 1 & 1 & 1 & 1 & 1 & 1 & 1 & 1\end{array}$ $\begin{array}{lllllllllllllllllllllllllllllllllllllllllllllllllllllll}1 & 1 & 1 & 1 & 1 & 1 & 1 & 1 & 1 & 1 & 1 & 1 & 1 & 1 & 1 & 1 & 1 & 1 & 1 & 1 & 1 & 1 & 1 & 1 & 1 & 1 & 1 & 1 & 1 & 1 & 1 & 1 & 1 & 1 & 1 & 1 & 1 & 1 & 1 & 1 & 1 & 1 & 1 & 1 & 1\end{array}$ $\begin{array}{llllllllllllllllllllllllllllllllllllllllllllll}1 & 1 & 1 & 1 & 1 & 1 & 1 & 1 & 1 & 1 & 1 & 1 & 1 & 1 & 1 & 1 & 1 & 1 & 1 & 1 & 1 & 1 & 1 & 1 & 1 & 1 & 1 & 1 & 1 & 1 & 1 & 1 & 1 & 1 & 1 & 1 & 1 & 1 & 1 & 1 & 1 & 1 & 1 & 1 & 1\end{array}$ $\begin{array}{llllllllllllllllllllllllllllllllllllllllllllllllllllllll}1 & 1 & 1 & 1 & 1 & 1 & 1 & 1 & 1 & 1 & 1 & 1 & 1 & 1 & 1 & 1 & 1 & 1 & 1 & 1 & 1 & 1 & 1 & 1 & 1 & 1 & 1 & 1 & 1 & 1 & 1 & 1 & 1 & 1 & 1 & 1 & 1 & 1 & 1 & 1 & 1 & 1 & 1 & 1 & 1\end{array}$ $\begin{array}{llllllllllllllllllllllllllllllllllllllllllllllllllllllll}1 & 1 & 1 & 1 & 1 & 1 & 1 & 1 & 1 & 1 & 1 & 1 & 1 & 1 & 1 & 1 & 1 & 1 & 1 & 1 & 1 & 1 & 1 & 1 & 1 & 1 & 1 & 1 & 1 & 1 & 1 & 1 & 1 & 1 & 1 & 1 & 1 & 1 & 1 & 1 & 1 & 1 & 1 & 1 & 1\end{array}$ $\begin{array}{llllllllllllllllllllllllllllllllllllllllllllll}1 & 1 & 1 & 1 & 1 & 1 & 1 & 1 & 1 & 1 & 1 & 1 & 1 & 1 & 1 & 1 & 1 & 1 & 1 & 1 & 1 & 1 & 1 & 1 & 1 & 1 & 1 & 1 & 1 & 1 & 1 & 1 & 1 & 1 & 1 & 1 & 1 & 1 & 1 & 1 & 1 & 1 & 1 & 1 & 1\end{array}$ $\begin{array}{lllllllllllllllllllllllllllllllllllllllllllllllllll}1 & 1 & 1 & 1 & 1 & 1 & 1 & 1 & 1 & 1 & 1 & 1 & 1 & 1 & 1 & 1 & 1 & 1 & 1 & 1 & 1 & 1 & 1 & 1 & 1 & 1 & 1 & 1 & 1 & 1 & 1 & 1 & 1 & 1 & 1 & 1 & 1 & 1 & 1 & 1 & 1 & 1 & 1 & 1 & 1\end{array}$ $\begin{array}{lllllllllllllllllllllllllllllllllllllllllllllllllll}1 & 1 & 1 & 1 & 1 & 1 & 1 & 1 & 1 & 1 & 1 & 1 & 1 & 1 & 1 & 1 & 1 & 1 & 1 & 1 & 1 & 1 & 1 & 1 & 1 & 1 & 1 & 1 & 1 & 1 & 1 & 1 & 1 & 1 & 1 & 1 & 1 & 1 & 1 & 1 & 1 & 1 & 1 & 1 & 1\end{array}$ $\begin{array}{llllllllllllllllllllllllllllllllllllllllllllllllll}1 & 1 & 1 & 1 & 1 & 1 & 1 & 1 & 1 & 1 & 1 & 1 & 1 & 1 & 1 & 1 & 1 & 1 & 1 & 1 & 1 & 1 & 1 & 1 & 1 & 1 & 1 & 1 & 1 & 1 & 1 & 1 & 1 & 1 & 1 & 1 & 1 & 1 & 1 & 1 & 1 & 1 & 1 & 1 & 1\end{array}$ $\begin{array}{llllllllllllllllllllllllllllllllllllllllllllll}1 & 1 & 1 & 1 & 1 & 1 & 1 & 1 & 1 & 1 & 1 & 1 & 1 & 1 & 1 & 1 & 1 & 1 & 1 & 1 & 1 & 1 & 1 & 1 & 1 & 1 & 1 & 1 & 1 & 1 & 1 & 1 & 1 & 1 & 1 & 1 & 1 & 1 & 1 & 1 & 1 & 1 & 1 & 1 & 1\end{array}$ $\begin{array}{llllllllllllllllllllllllllllllllllllllllllllll}1 & 1 & 1 & 1 & 1 & 1 & 1 & 1 & 1 & 1 & 1 & 1 & 1 & 1 & 1 & 1 & 1 & 1 & 1 & 1 & 1 & 1 & 1 & 1 & 1 & 1 & 1 & 1 & 1 & 1 & 1 & 1 & 1 & 1 & 1 & 1 & 1 & 1 & 1 & 1 & 1 & 1 & 1 & 1 & 1\end{array}$ $\begin{array}{llllllllllllllllllllllllllllllllllllllllllllllllll}1 & 1 & 1 & 1 & 1 & 1 & 1 & 1 & 1 & 1 & 1 & 1 & 1 & 1 & 1 & 1 & 1 & 1 & 1 & 1 & 1 & 1 & 1 & 1 & 1 & 1 & 1 & 1 & 1 & 1 & 1 & 1 & 1 & 1 & 1 & 1 & 1 & 1 & 1 & 1 & 1 & 1 & 1 & 1 & 1\end{array}$ $\begin{array}{lllllllllllllllllllllllllllllllllllllllllllllllllll}1 & 1 & 1 & 1 & 1 & 1 & 1 & 1 & 1 & 1 & 1 & 1 & 1 & 1 & 1 & 1 & 1 & 1 & 1 & 1 & 1 & 1 & 1 & 1 & 1 & 1 & 1 & 1 & 1 & 1 & 1 & 1 & 1 & 1 & 1 & 1 & 1 & 1 & 1 & 1 & 1 & 1 & 1 & 1 & 1\end{array}$ $\begin{array}{lllllllllllllllllllllllllllllllllllllllllllllllllllllll}1 & 1 & 1 & 1 & 1 & 1 & 1 & 1 & 1 & 1 & 1 & 1 & 1 & 1 & 1 & 1 & 1 & 1 & 1 & 1 & 1 & 1 & 1 & 1 & 1 & 1 & 1 & 1 & 1 & 1 & 1 & 1 & 1 & 1 & 1 & 1 & 1 & 1 & 1 & 1 & 1 & 1 & 1 & 1 & 1\end{array}$ $\begin{array}{llllllllllllllllllllllllllllllllllllllllllllllllll}1 & 1 & 1 & 1 & 1 & 1 & 1 & 1 & 1 & 1 & 1 & 1 & 1 & 1 & 1 & 1 & 1 & 1 & 1 & 1 & 1 & 1 & 1 & 1 & 1 & 1 & 1 & 1 & 1 & 1 & 1 & 1 & 1 & 1 & 1 & 1 & 1 & 1 & 1 & 1 & 1 & 1 & 1 & 1 & 1\end{array}$ $\begin{array}{llllllllllllllllllllllllllllllllllllllllllllllllll}1 & 1 & 1 & 1 & 1 & 1 & 1 & 1 & 1 & 1 & 1 & 1 & 1 & 1 & 1 & 1 & 1 & 1 & 1 & 1 & 1 & 1 & 1 & 1 & 1 & 1 & 1 & 1 & 1 & 1 & 1 & 1 & 1 & 1 & 1 & 1 & 1 & 1 & 1 & 1 & 1 & 1 & 1 & 1 & 1\end{array}$

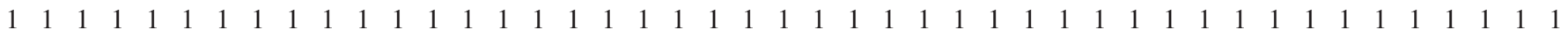
$\begin{array}{llllllllllllllllllllllllllllllllllllllllllllll}1 & 1 & 1 & 1 & 1 & 1 & 1 & 1 & 1 & 1 & 1 & 1 & 1 & 1 & 1 & 1 & 1 & 1 & 1 & 1 & 1 & 1 & 1 & 1 & 1 & 1 & 1 & 1 & 1 & 1 & 1 & 1 & 1 & 1 & 1 & 1 & 1 & 1 & 1 & 1 & 1 & 1 & 1 & 1 & 1\end{array}$

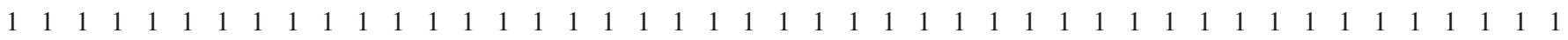
$\begin{array}{lllllllllllllllllllllllllllllllllllllllllllllllllll}1 & 1 & 1 & 1 & 1 & 1 & 1 & 1 & 1 & 1 & 1 & 1 & 1 & 1 & 1 & 1 & 1 & 1 & 1 & 1 & 1 & 1 & 1 & 1 & 1 & 1 & 1 & 1 & 1 & 1 & 1 & 1 & 1 & 1 & 1 & 1 & 1 & 1 & 1 & 1 & 1 & 1 & 1 & 1 & 1\end{array}$

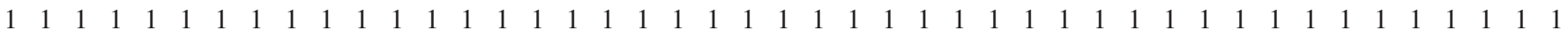
$\begin{array}{llllllllllllllllllllllllllllllllllllllllllllllllllllll}1 & 1 & 1 & 1 & 1 & 1 & 1 & 1 & 1 & 1 & 1 & 1 & 1 & 1 & 1 & 1 & 1 & 1 & 1 & 1 & 1 & 1 & 1 & 1 & 1 & 1 & 1 & 1 & 1 & 1 & 1 & 1 & 1 & 1 & 1 & 1 & 1 & 1 & 1 & 1 & 1 & 1 & 1 & 1 & 1\end{array}$ $\begin{array}{llllllllllllllllllllllllllllllllllllllllllllll}1 & 1 & 1 & 1 & 1 & 1 & 1 & 1 & 1 & 1 & 1 & 1 & 1 & 1 & 1 & 1 & 1 & 1 & 1 & 1 & 1 & 1 & 1 & 1 & 1 & 1 & 1 & 1 & 1 & 1 & 1 & 1 & 1 & 1 & 1 & 1 & 1 & 1 & 1 & 1 & 1 & 1 & 1 & 1 & 1\end{array}$ $\begin{array}{llllllllllllllllllllllllllllllllllllllllllllllllllll}1 & 1 & 1 & 1 & 1 & 1 & 1 & 1 & 1 & 1 & 1 & 1 & 1 & 1 & 1 & 1 & 1 & 1 & 1 & 1 & 1 & 1 & 1 & 1 & 1 & 1 & 1 & 1 & 1 & 1 & 1 & 1 & 1 & 1 & 1 & 1 & 1 & 1 & 1 & 1 & 1 & 1 & 1 & 1 & 1\end{array}$ $\begin{array}{llllllllllllllllllllllllllllllllllllllllllllllllllllll}1 & 1 & 1 & 1 & 1 & 1 & 1 & 1 & 1 & 1 & 1 & 1 & 1 & 1 & 1 & 1 & 1 & 1 & 1 & 1 & 1 & 1 & 1 & 1 & 1 & 1 & 1 & 1 & 1 & 1 & 1 & 1 & 1 & 1 & 1 & 1 & 1 & 1 & 1 & 1 & 1 & 1 & 1 & 1 & 1\end{array}$ $\begin{array}{llllllllllllllllllllllllllllllllllllllllllllll}1 & 1 & 1 & 1 & 1 & 1 & 1 & 1 & 1 & 1 & 1 & 1 & 1 & 1 & 1 & 1 & 1 & 1 & 1 & 1 & 1 & 1 & 1 & 1 & 1 & 1 & 1 & 1 & 1 & 1 & 1 & 1 & 1 & 1 & 1 & 1 & 1 & 1 & 1 & 1 & 1 & 1 & 1 & 1 & 1\end{array}$ $\begin{array}{llllllllllllllllllllllllllllllllllllllllllllll}1 & 1 & 1 & 1 & 1 & 1 & 1 & 1 & 1 & 1 & 1 & 1 & 1 & 1 & 1 & 1 & 1 & 1 & 1 & 1 & 1 & 1 & 1 & 1 & 1 & 1 & 1 & 1 & 1 & 1 & 1 & 1 & 1 & 1 & 1 & 1 & 1 & 1 & 1 & 1 & 1 & 1 & 1 & 1 & 1\end{array}$ $\begin{array}{llllllllllllllllllllllllllllllllllllllllllllll}1 & 1 & 1 & 1 & 1 & 1 & 1 & 1 & 1 & 1 & 1 & 1 & 1 & 1 & 1 & 1 & 1 & 1 & 1 & 1 & 1 & 1 & 1 & 1 & 1 & 1 & 1 & 1 & 1 & 1 & 1 & 1 & 1 & 1 & 1 & 1 & 1 & 1 & 1 & 1 & 1 & 1 & 1 & 1 & 1\end{array}$ 


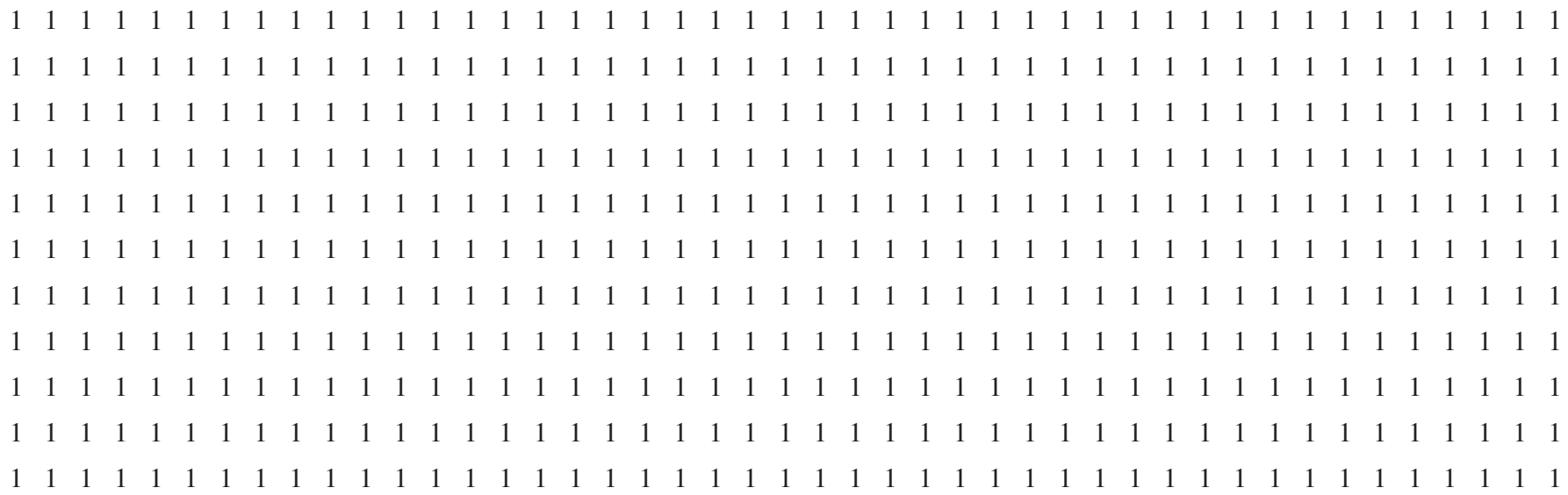

Zone array generated by the interactive response is reprinted here for reference.

CONCENTRATIONS $\quad$ LAYER $=1 \quad$ SLAYER $=1 \quad$ TIME $=1051900.00$

Print of concentration header for specified time.

\begin{tabular}{|c|c|c|c|c|c|c|}
\hline $\mathrm{MNCOL}=45$ & MNROW = & & & & & \\
\hline $0.4222 \mathrm{E}-37$ & $-0.2152 \mathrm{E}-36$ & $-0.3296 \mathrm{E}-37$ & $0.2412 \mathrm{E}-36$ & $-0.6368 \mathrm{E}-36$ & $-0.2714 \mathrm{E}-36$ & -999.9 \\
\hline-999.9 & -999.9 & -999.9 & -999.9 & -999.9 & -999.9 & -999.9 \\
\hline-999.9 & -999.9 & -999.9 & -999.9 & -999.9 & -999.9 & -999.9 \\
\hline-999.9 & -999.9 & -999.9 & -999.9 & -999.9 & -999.9 & -999.9 \\
\hline-999.9 & -999.9 & -999.9 & -999.9 & -999.9 & -999.9 & -999.9 \\
\hline-999.9 & -999.9 & -999.9 & -999.9 & -999.9 & -999.9 & -999.9 \\
\hline-999.9 & -999.9 & -999.9 & & & & \\
\hline
\end{tabular}

Check file prints out last row of concentration data from that time period.

PRINT STATS FOR $=54 \quad 54 \quad 45 \quad 45$ zone 1

Print display indicates data are being sent to main output file for that zone for each time period.

\begin{tabular}{|c|c|c|c|c|c|c|}
\hline \multicolumn{7}{|c|}{ CONCENTRATIONS } \\
\hline$-0.7338 \mathrm{E}-31$ & $-0.6356 \mathrm{E}-30$ & $-0.4778 \mathrm{E}-31$ & $-0.4156 \mathrm{E}-31$ & $0.2241 \mathrm{E}-30$ & $0.1000 \mathrm{E}-31$ & -999.9 \\
\hline-999.9 & -999.9 & -999.9 & -999.9 & -999.9 & -999.9 & -999.9 \\
\hline-999.9 & -999.9 & -999.9 & -999.9 & -999.9 & -999.9 & -999.9 \\
\hline-999.9 & -999.9 & -999.9 & -999.9 & -999.9 & -999.9 & -999.9 \\
\hline-999.9 & -999.9 & -999.9 & -999.9 & -999.9 & -999.9 & -999.9 \\
\hline-999.9 & -999.9 & -999.9 & -999.9 & -999.9 & -999.9 & -999.9 \\
\hline-999.9 & -999.9 & -999.9 & & & & \\
\hline
\end{tabular}

PRINT STATS FOR $=\begin{array}{lllll}54 & 54 & 45 & 45 & \text { zone } 1\end{array}$

\begin{tabular}{|c|c|c|c|c|c|c|}
\hline \multicolumn{2}{|c|}{ CONCENTRATIONS } & $\mathrm{R}=1 \quad \mathrm{SLAY}$ & \multicolumn{2}{|c|}{ TIME $=3155800.00$} & $\mathrm{MNCOL}=45$ & \multirow{2}{*}{$\begin{array}{c}\text { MNROW }=54 \\
-999.9\end{array}$} \\
\hline 0.1059E-29 & $0.3951 \mathrm{E}-28$ & $0.1060 \mathrm{E}-27$ & $0.1302 \mathrm{E}-28$ & $-0.6193 \mathrm{E}-29$ & $0.1785 \mathrm{E}-30$ & \\
\hline-999.9 & -999.9 & -999.9 & -999.9 & -999.9 & -999.9 & -999.9 \\
\hline-999.9 & -999.9 & -999.9 & -999.9 & -999.9 & -999.9 & -999.9 \\
\hline-999.9 & -999.9 & -999.9 & -999.9 & -999.9 & -999.9 & -999.9 \\
\hline-999.9 & -999.9 & -999.9 & -999.9 & -999.9 & -999.9 & -999.9 \\
\hline-999.9 & -999.9 & -999.9 & -999.9 & -999.9 & -999.9 & -999.9 \\
\hline-999.9 & -999.9 & -999.9 & & & & \\
\hline \multicolumn{5}{|c|}{ PRINT STATS FOR = $54 \quad 54 \quad 45 \quad 45$ zone 1} & & \\
\hline \multicolumn{5}{|c|}{ CONCENTRATIONS $\quad$ LAYER $=1 \quad$ SLAYER $=1 \quad$ TIME $=4207700.00$} & $\mathrm{MNCOL}=45$ & MNROW $=54$ \\
\hline$-0.1193 \mathrm{E}-28$ & $0.1957 \mathrm{E}-27$ & $0.1128 \mathrm{E}-27$ & $0.6021 \mathrm{E}-29$ & $0.4223 \mathrm{E}-30$ & $0.2533 \mathrm{E}-29$ & -999.9 \\
\hline-999.9 & -999.9 & -999.9 & -999.9 & -999.9 & -999.9 & -999.9 \\
\hline-999.9 & -999.9 & -999.9 & -999.9 & -999.9 & -999.9 & -999.9 \\
\hline-999.9 & -999.9 & -999.9 & -999.9 & -999.9 & -999.9 & -999.9 \\
\hline-999.9 & -999.9 & -999.9 & -999.9 & -999.9 & -999.9 & -999.9 \\
\hline-999.9 & -999.9 & -999.9 & -999.9 & -999.9 & -999.9 & -999.9 \\
\hline-999.9 & -999.9 & -999.9 & & & & \\
\hline
\end{tabular}

PRINT STATS FOR $=\begin{array}{lllll}54 & 54 & 45 & 45 & \text { zone } 1\end{array}$ 


\begin{tabular}{|c|c|c|c|c|c|c|}
\hline \multicolumn{5}{|c|}{ CONCENTRATIONS } & \multirow{2}{*}{$\begin{array}{r}\mathrm{MNCOL}=45 \\
0.3687 \mathrm{E}-29\end{array}$} & \multirow{2}{*}{$\begin{array}{c}\text { MNROW }=54 \\
-999.9\end{array}$} \\
\hline$-0.1848 \mathrm{E}-28$ & $0.3578 \mathrm{E}-27$ & $0.1117 \mathrm{E}-27$ & $0.1127 \mathrm{E}-28$ & $0.2736 \mathrm{E}-29$ & & \\
\hline-999.9 & -999.9 & -999.9 & -999.9 & -999.9 & -999.9 & -999.9 \\
\hline-999.9 & -999.9 & -999.9 & -999.9 & -999.9 & -999.9 & -999.9 \\
\hline-999.9 & -999.9 & -999.9 & -999.9 & -999.9 & -999.9 & -999.9 \\
\hline-999.9 & -999.9 & -999.9 & -999.9 & -999.9 & -999.9 & -999.9 \\
\hline-999.9 & -999.9 & -999.9 & -999.9 & -999.9 & -999.9 & -999.9 \\
\hline-999.9 & -999.9 & -999.9 & & & & \\
\hline \multicolumn{5}{|c|}{ PRINT STATS FOR = $54 \quad 54 \quad 45 \quad 45$ zone 1} & & \\
\hline \multicolumn{5}{|c|}{ CONCENTRATIONS } & $\mathrm{MNCOL}=45$ & MNROW $=54$ \\
\hline$-0.1830 \mathrm{E}-28$ & $0.5273 \mathrm{E}-27$ & $0.9745 \mathrm{E}-28$ & $0.2327 \mathrm{E}-28$ & $0.8848 \mathrm{E}-31$ & $0.3224 \mathrm{E}-29$ & -999.9 \\
\hline-999.9 & -999.9 & -999.9 & -999.9 & -999.9 & -999.9 & -999.9 \\
\hline-999.9 & -999.9 & -999.9 & -999.9 & -999.9 & -999.9 & -999.9 \\
\hline-999.9 & -999.9 & -999.9 & -999.9 & -999.9 & -999.9 & -999.9 \\
\hline-999.9 & -999.9 & -999.9 & -999.9 & -999.9 & -999.9 & -999.9 \\
\hline-999.9 & -999.9 & -999.9 & -999.9 & -999.9 & -999.9 & -999.9 \\
\hline-999.9 & -999.9 & -999.9 & & & & \\
\hline
\end{tabular}

PRINT STATS FOR $=54 \quad 54 \quad 45 \quad 45$ zone 1

The above printout can be examined to determine if concentration data from the CNCA file are being read correctly by ZONECONC. 


\section{APPENDIX 2. Example of ZONECONC with Solute-Transport Model of a Hypothetical Barrier Wall}

Simulations from a solute-transport model of a hypothetical barrier wall (P.T. Harte, U.S. Geological Survey, written commun., 2005) were analyzed using ZONECONC version 1.5. Two ZONECONC tests were run on the model of the hypothetical barrier wall.

The model grid is one layer with 19 rows and 28 columns (fig. 2-1). In this example, the grid and subgrid are the same. Grid cell sizes are uniform and square in shape (25 feet). Specified-head-boundary conditions (negative ibound numbers) occur on the west and east model boundaries. The constant heads produce a west-to-east flow system with a horizontal head gradient of 0.014 foot/foot. A low-permeability barrier wall is in the middle of the grid. The barrier wall covers an area of about 4-9 cells across. Constant contaminant (tetrachloroethylene) concentrations of 100,000 microgram per liter $(\mu \mathrm{g} / \mathrm{L}$ or parts per billion $(\mathrm{ppb}))$ are specified inside the barrier wall. Outside the barrier, the initial concentration is zero. A specified gradient inside the barrier is simulated to produce a slight outward gradient of ground-water flow on the eastern, downgradient side of the flow system. This gradient produces slow leakage of contaminants from inside the barrier where contamination is present to outside the barrier where ground water is initially clean. Therefore, during the course of the simulation, all concentrations outside the barrier result from leakage through the barrier.

The data sets used for the ZONECONC analysis are from simulation number bar3gg (DOUT-3; P.T. Harte, U.S. Geological Survey, written commun., 2005). Bar3gg is a direct simulation where cells in the grid are assigned the lowest estimated horizontal hydraulic conductivity value for the barrier, about 10,000 times lower than the aquifer, to correspond to the location of the barrier wall. The simulation includes an assigned outward head gradient to induce outward flow from inside to outside the barrier. Concentration data consist of two time periods (initial and final (10 years, 3,652.5 days in model units)).

Two example sessions are provided to show the utility of ZONECONC. The first ZONECONC test uses the interactive (user defined) zone option, which uses the ZONEBUDGET subroutine BLOCK (Harbaugh, 1990). The option to use an external zone file was used in the second test. With this option, the ZONEBUDGET subroutine IZREAD is used (Harbaugh, 1990). In the second test, the interior barrier cells are designated with a unique zone number to track concentration differences inside and outside of the barrier.

\section{Reference Cited}

Harbaugh, A.W., 1990, A computer program for calculating subregional water budgets using results from the U.S. Geological Survey modular three-dimensional finite-difference ground-water model: U.S. Geological Survey Open-File Report 90-392, $24 \mathrm{p}$.

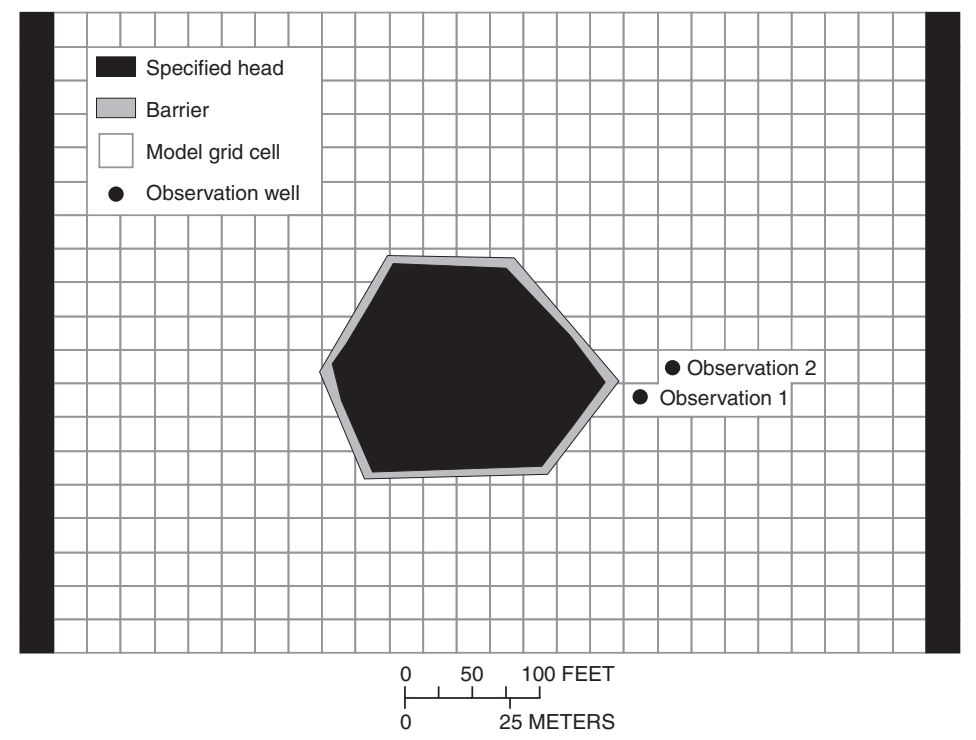

Figure 2-1. Example of a solutetransport model of a hypothetical barrier wall. 


\section{Example test run 1: Interactive (user-defined) designation of zone values for the model.}

1. Input instructions follow (Unbolded font is program prompts and output, bold is user typed response, red is author commentary (not provided in program).

Enter Input CNCA FILE NAME:

bar3gg.cna

INPUT NAME IS: bar3gg.cna

ENTER OUTPUT FILE NAME 1:

run3gg51

ENTER INPUT GWT FILE NAME:

bar3gg.moc

INPUT NAME IS: bar3gg.moc

21119128

SUBGRID ROWS $=19$, SUBGRID COLUMNS $=28$

SUBGRID LAYERS $=1$

INPUT DISCRETIZATION FILE NAME:

bartest7.dis

INPUT NAME IS: bartest7.dis

MODEL LAYERS $=1$ ROWS $=19$ COLS $=28$

ENTER OUTPUT FILE TO WRITE CONC. ARRAY:

C3gg51

Enter the name of your ZONE INPUT FILE $<\mathrm{cr}=$ interactive:

$<$ cr>

Enter the start layer, stop layer $<0,0$ means done $>$ :

1,1

Only one layer of zone.

Enter the start row, stop row:

1,19

All rows are included in this zone.

Enter the start column, stop column:

1,28

All columns are included in this zone.

Enter the zone for this block, must no. incremental:

1

Enter the start layer, stop layer $<0,0$ means done $>$ :

$\mathbf{0 , 0}$

This response means stop. Therefore, only one zone is created.

TIME $=0.00000, \#$ of Headers read 1

TIME $=3652.5$, \# of Headers read 2

Concentration headers read in the CNCA file are displayed here. The CNCA file prints a header for each time period and layer (only 1 in this case).

1064 = NUMBER OF ACTIVE CONC. CELLS COUNTED

The number of non-negative concentration values in the CNCA file are displayed here. The concentration array size can be checked by dividing the number of active cells by the number of headers. In this case, 532 cells for a 19 by 28 grid.

Program Completed

Press Enter to Continue.

$<\mathrm{CR}>$ 
2. Output example 1 from the main output file.

\author{
ZONECONC VERSION 1.50 \\ SUMMARY STATS PER LAYER AND ZONE, RUN = bar3gg.cna \\ OUTPUT FILE NAME $=$ r3gg51 \\ Zone block: LAYERS 1- 1 ROWS 1- 19 COLUMNS 1- 28 VALUE: 1 \\ NUMBER OF ZONES: 1 \\ READING CONCENTRATION DATA
}

\begin{tabular}{|c|c|c|c|c|c|c|c|c|c|c|c|}
\hline TIME & ZONE & MAX. & ROW & COL. & LAYER & MIN. & MEAN & TOTAL & COUNT & PCOUNT & STAND. DEV. \\
\hline 0.00000 & 1 & $0.1000 \mathrm{E}+06$ & 13 & 15 & 1 & $0.0000 \mathrm{E}+00$ & $0.4135 \mathrm{E}+04$ & $0.2200 \mathrm{E}+07$ & 532 & 22 & $0.1988 \mathrm{E}+05$ \\
\hline 3652.50 & 1 & $0.1000 \mathrm{E}+06$ & 13 & 13 & 1 & $0.6430 \mathrm{E}-04$ & $0.4134 \mathrm{E}+04$ & $0.2199 \mathrm{E}+07$ & 532 & 532 & $0.1984 \mathrm{E}+05$ \\
\hline
\end{tabular}

Two time periods are listed for the one zone. The maximum concentration of 100,000 ppb is from the specified concentration cells inside the barrier, which occurs at multiple cells. ZONECONC lists two different cells, row 13 and column 15 and row 13 column 13, for the two time periods because the program can not differentiate an identical maximum concentration location. As a result, the program will print the last cell location read with the same identical maximum concentration. The mean for the entire grid (one zone) is $4,135 \mathrm{ppb}$ at time $=0$ and $4,134 \mathrm{ppb}$ at time $=3,652.5$ days or 10 years. The standard deviation is large because cells outside the barrier have an initial concentration of zero. For time period at zero, only the 22 cells inside the barrier have a positive concentration (PCOUNT). For the time period at 3,653 days, all cells have a slight positive concentration. Nonnegative concentrations occur and that is why COUNT equals the total number of cells.

\title{
Example test run 2: External zone file given.
}

\section{Input instructions follow (bold is user-typed response).}

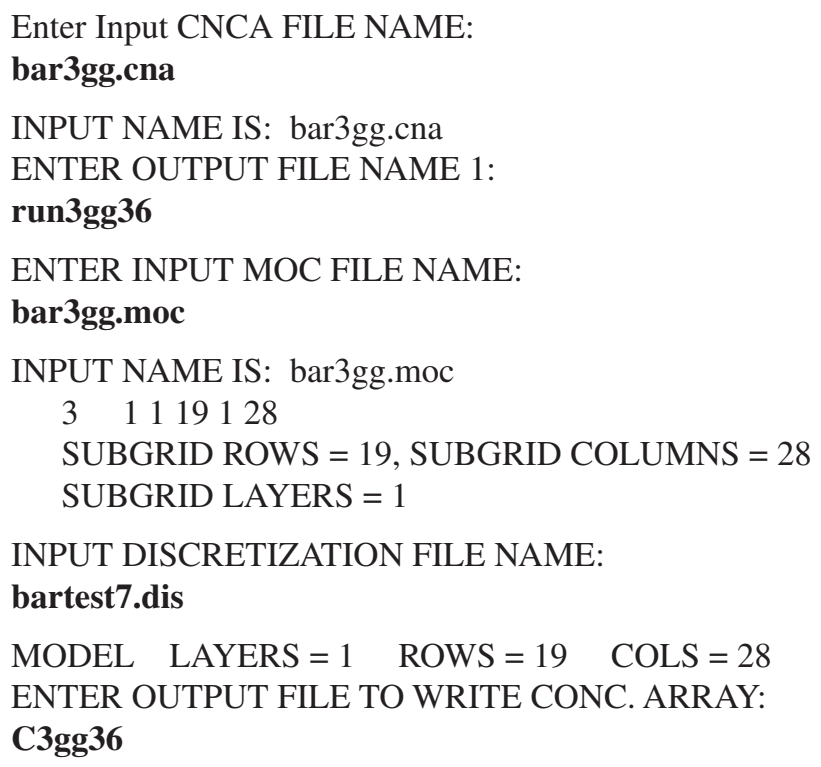


2. Output example 2 from the main output.

ZONECONC VERSION 1.50

SUMMARY STATS PER LAYER AND ZONE, RUN = bar3gg.cna

OUTPUT FILE NAME $=$ run3gg52

The zone file is:

izonebar3hh3.i0

11928

READING ZONE DATA

INTERNAL

Zone Array for layer 1 will be read from the Zone File

Zone Array for layer 1 will be read using format: (28I6)

$\begin{array}{llllllllllllllllllllllllllllll} & 1 & 2 & 3 & 4 & 5 & 6 & 7 & 8 & 9 & 10 & 11 & 12 & 13 & 14 & 15 & 16 & 17 & 18 & 19 & 20 & 21 & 22 & 23 & 24 & 25 & 26 & 27 & 28 \\ 1 & 1 & 1 & 1 & 1 & 1 & 1 & 1 & 1 & 1 & 1 & 1 & 1 & 1 & 1 & 1 & 1 & 1 & 1 & 1 & 1 & 1 & 1 & 1 & 1 & 1 & 1 & 1 & 1 \\ 2 & 1 & 1 & 1 & 1 & 1 & 1 & 1 & 1 & 1 & 1 & 1 & 1 & 1 & 1 & 1 & 1 & 1 & 1 & 1 & 1 & 1 & 1 & 1 & 1 & 1 & 1 & 1 & 1 \\ 3 & 1 & 1 & 1 & 1 & 1 & 1 & 1 & 1 & 1 & 1 & 1 & 1 & 1 & 1 & 1 & 1 & 1 & 1 & 1 & 1 & 1 & 1 & 1 & 1 & 1 & 1 & 1 & 1 \\ 4 & 1 & 1 & 1 & 1 & 1 & 1 & 1 & 1 & 1 & 1 & 1 & 1 & 1 & 1 & 1 & 1 & 1 & 1 & 1 & 1 & 1 & 1 & 1 & 1 & 1 & 1 & 1 & 1 \\ 5 & 1 & 1 & 1 & 1 & 1 & 1 & 1 & 1 & 1 & 1 & 1 & 1 & 1 & 1 & 1 & 1 & 1 & 1 & 1 & 1 & 1 & 1 & 1 & 1 & 1 & 1 & 1 & 1 \\ 6 & 1 & 1 & 1 & 1 & 1 & 1 & 1 & 1 & 1 & 1 & 1 & 1 & 1 & 1 & 1 & 1 & 1 & 1 & 1 & 1 & 1 & 1 & 1 & 1 & 1 & 1 & 1 & 1 \\ 7 & 1 & 1 & 1 & 1 & 1 & 1 & 1 & 1 & 1 & 1 & 1 & 1 & 1 & 1 & 1 & 1 & 1 & 1 & 1 & 1 & 1 & 1 & 1 & 1 & 1 & 1 & 1 & 1 \\ 8 & 1 & 1 & 1 & 1 & 1 & 1 & 1 & 1 & 1 & 1 & 1 & 2 & 2 & 2 & 1 & 1 & 1 & 1 & 1 & 1 & 1 & 1 & 1 & 1 & 1 & 1 & 1 & 1 \\ 9 & 1 & 1 & 1 & 1 & 1 & 1 & 1 & 1 & 1 & 1 & 2 & 2 & 2 & 2 & 2 & 1 & 1 & 1 & 1 & 1 & 1 & 1 & 1 & 1 & 1 & 1 & 1 & 1 \\ 10 & 1 & 1 & 1 & 1 & 1 & 1 & 1 & 1 & 1 & 1 & 2 & 2 & 2 & 2 & 2 & 2 & 1 & 1 & 1 & 1 & 1 & 1 & 1 & 1 & 1 & 1 & 1 & 1 \\ 11 & 1 & 1 & 1 & 1 & 1 & 1 & 1 & 1 & 1 & 2 & 2 & 2 & 2 & 2 & 2 & 2 & 2 & 1 & 1 & 1 & 1 & 1 & 1 & 1 & 1 & 1 & 1 & 1 \\ 12 & 1 & 1 & 1 & 1 & 1 & 1 & 1 & 1 & 1 & 2 & 2 & 2 & 2 & 2 & 2 & 2 & 2 & 1 & 1 & 1 & 1 & 1 & 1 & 1 & 1 & 1 & 1 & 1 \\ 13 & 1 & 1 & 1 & 1 & 1 & 1 & 1 & 1 & 1 & 1 & 2 & 2 & 2 & 2 & 2 & 2 & 1 & 1 & 1 & 1 & 1 & 1 & 1 & 1 & 1 & 1 & 1 & 1 \\ 14 & 1 & 1 & 1 & 1 & 1 & 1 & 1 & 1 & 1 & 1 & 2 & 2 & 2 & 1 & 1 & 1 & 1 & 1 & 1 & 1 & 1 & 1 & 1 & 1 & 1 & 1 & 1 & 1 \\ 15 & 1 & 1 & 1 & 1 & 1 & 1 & 1 & 1 & 1 & 1 & 1 & 1 & 1 & 1 & 1 & 1 & 1 & 1 & 1 & 1 & 1 & 1 & 1 & 1 & 1 & 1 & 1 & 1 \\ 16 & 1 & 1 & 1 & 1 & 1 & 1 & 1 & 1 & 1 & 1 & 1 & 1 & 1 & 1 & 1 & 1 & 1 & 1 & 1 & 1 & 1 & 1 & 1 & 1 & 1 & 1 & 1 & 1 \\ 17 & 1 & 1 & 1 & 1 & 1 & 1 & 1 & 1 & 1 & 1 & 1 & 1 & 1 & 1 & 1 & 1 & 1 & 1 & 1 & 1 & 1 & 1 & 1 & 1 & 1 & 1 & 1 & 1 \\ 18 & 1 & 1 & 1 & 1 & 1 & 1 & 1 & 1 & 1 & 1 & 1 & 1 & 1 & 1 & 1 & 1 & 1 & 1 & 1 & 1 & 1 & 1 & 1 & 1 & 1 & 1 & 1 & 1 \\ 19 & 1 & 1 & 1 & 1 & 1 & 1 & 1 & 1 & 1 & 1 & 1 & 1 & 1 & 1 & 1 & 1 & 1 & 1 & 1 & 1 & 1 & 1 & 1 & 1 & 1 & 1 & 1 & 1\end{array}$

NUMBER OF ZONES: 2

READING CONCENTRATION DATA

STATISTICS ARE CALCULATED ON NON-NEGATIVE (VALUES $=>0$ ) CONCENTRATION EXCEPT PCOUNT (VALUES $>0$ )

$\begin{array}{lclccclllrrr}\text { TIME } & \text { ZONE } & \text { MAX. } & \text { ROW } & \text { COL. } & \text { LAYER } & \text { MIN. } & \text { MEAN } & \text { TOTAL } & \text { COUNT } & \text { PCOUNT } & \text { STAND. DEV. } \\ 0.00000 & 1 & 0.0000 \mathrm{E}+00 & 19 & 28 & 1 & 0.0000 \mathrm{E}+00 & 0.0000 \mathrm{E}+00 & 0.0000 \mathrm{E}+00 & 493 & 0 & 0.0000 \mathrm{E}+00 \\ 0.00000 & 2 & 0.1000 \mathrm{E}+06 & 13 & 15 & 1 & 0.0000 \mathrm{E}+00 & 0.5641 \mathrm{E}+05 & 0.2200 \mathrm{E}+07 & 39 & 22 & 0.4788 \mathrm{E}+05 \\ 3652.50 & 1 & 0.8200 \mathrm{E}+01 & 12 & 18 & 1 & 0.6430 \mathrm{E}-04 & 0.4676 \mathrm{E}+00 & 0.2305 \mathrm{E}+03 & 493 & 493 & 0.7749 \mathrm{E}+00 \\ 3652.50 & 2 & 0.1000 \mathrm{E}+06 & 13 & 13 & 1 & 0.2400 \mathrm{E}-02 & 0.5639 \mathrm{E}+05 & 0.2199 \mathrm{E}+07 & 39 & 39 & 0.4768 \mathrm{E}+05\end{array}$

ZONECONC reproduces the zone input file in the main output file for cases where a zone file is specified. However, the main advantage to using the zone file is the ability to differentiate two zones, inside the barrier and outside, so that statistical analysis can be done for each area on the concentration data from the simulation. Here, the large difference in concentrations from inside the barrier and outside the barrier is apparent. The maximum concentration outside the barrier is $8.2 \mathrm{ppb}$ located at row 12 and column 18 . The standard deviation is large $(0.4768 \mathrm{E}+05)$ for inside the barrier because one cell is not assigned a specified concentration of 100,000 ppb. 


\section{APPENDIX 3. Example of ZONECONC with Steady-State Solute-Transport Model of the Savage Superfund Site, Milford, N.H.}

A simulation from the Savage Superfund site steady-state model of pre-remedial conditions (Harte, 2004, p. 25) was analyzed using ZONECONC version 1.5. The test used the option to interactively create zones in the model with ZONECONC.

This model example consists of 5 layers, 175 rows, and 189 columns (fig. 3-1). The grid and solute-transport subgrid are different and the subgrid-transport model starts at row 23 and ends at row 140 of the model grid. From rows 23 to 52, the model-grid cell size varies. The column for the subgrid starts at model column 25 and ends at model column 170. The simulation was solved with the ELLAM solver (Heberton and others, 2000) that allows non-uniform cell sizes to be used in the solute-transport model.

The steady-state model of pre-remedial conditions includes two time periods, the initial time and final time of 3.5 years (0.1105E+09 seconds in model units). Solutes (tetrachloroethylene) are present at initial time (fig. 3-2) and no further input of solutes occurs. The active simulated area includes the river-valley sediments (overburden) and not the underlying bedrock.

\section{References Cited}

Harbaugh, A.W., 1990, A computer program for calculating subregional water budgets using results from the U.S. Geological Survey modular three-dimensional finite-difference ground-water model: U.S. Geological Survey Open-File Report 90-392, $24 \mathrm{p}$.

Harte, P.T., 2004, Simulation of solute transport of tetrachloroethylene in ground water of the glacial-drift aquifer at the Savage Municipal Well Superfund site, Milford, New Hampshire, 1960-2000, U.S. Geological Survey Scientific Investigations Report 2004-5176, 84 p.

Heberton, C.I., Russell, T.F., Konikow, L.F., and Hornberger, G.Z., 2000, A three-dimensional finite-volume eulerian-lagrangian localized adjoint method (ellam) for solute transport modeling: U.S. Geological Survey Water-Resources Investigations Report 00-4087, 63 p. 


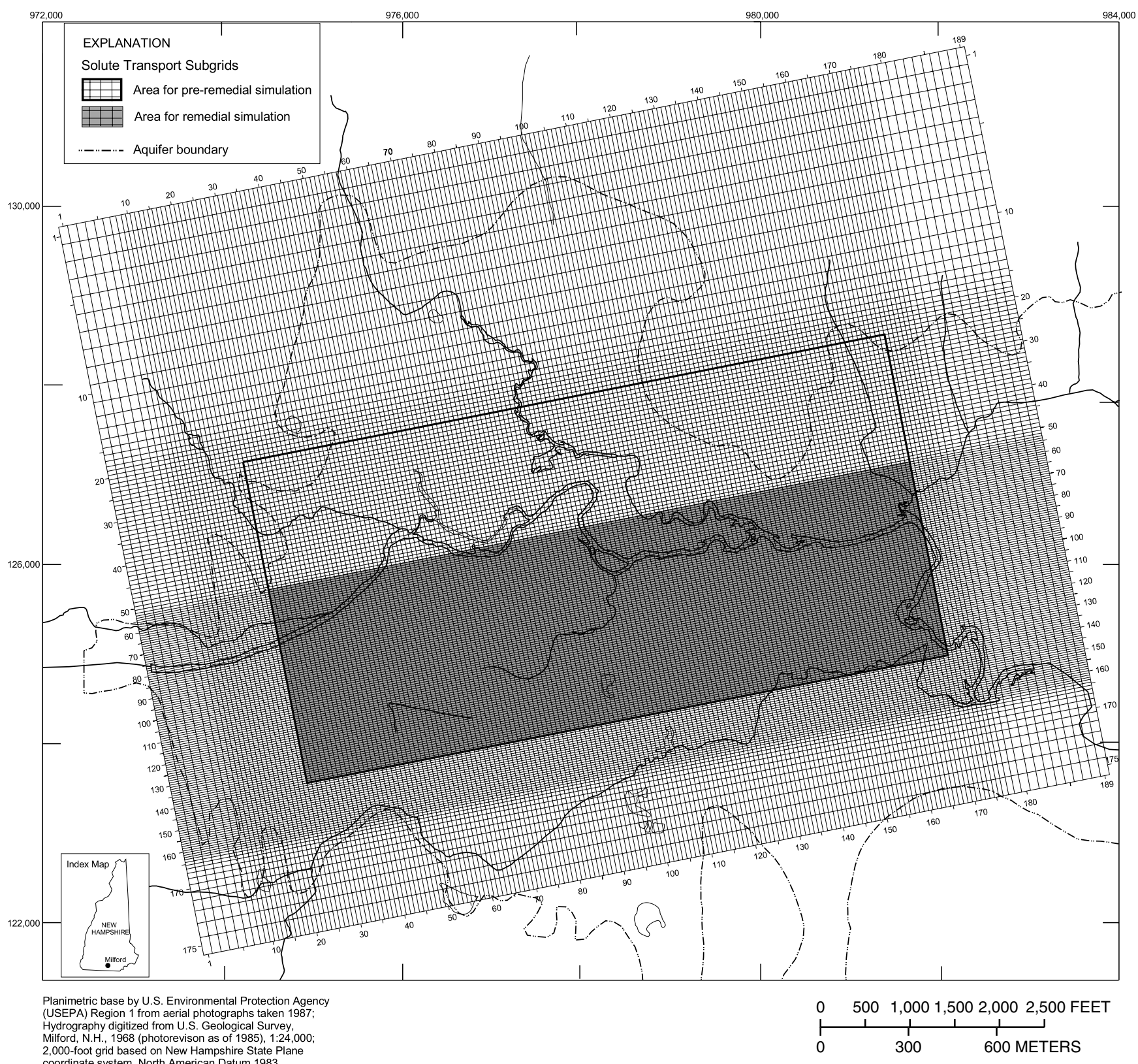

Figure 3-1. Example of the steady-state solute-transport model of the Savage Superfund site, Milford, N.H. (Modified from Harte, 2004, plate 4) 


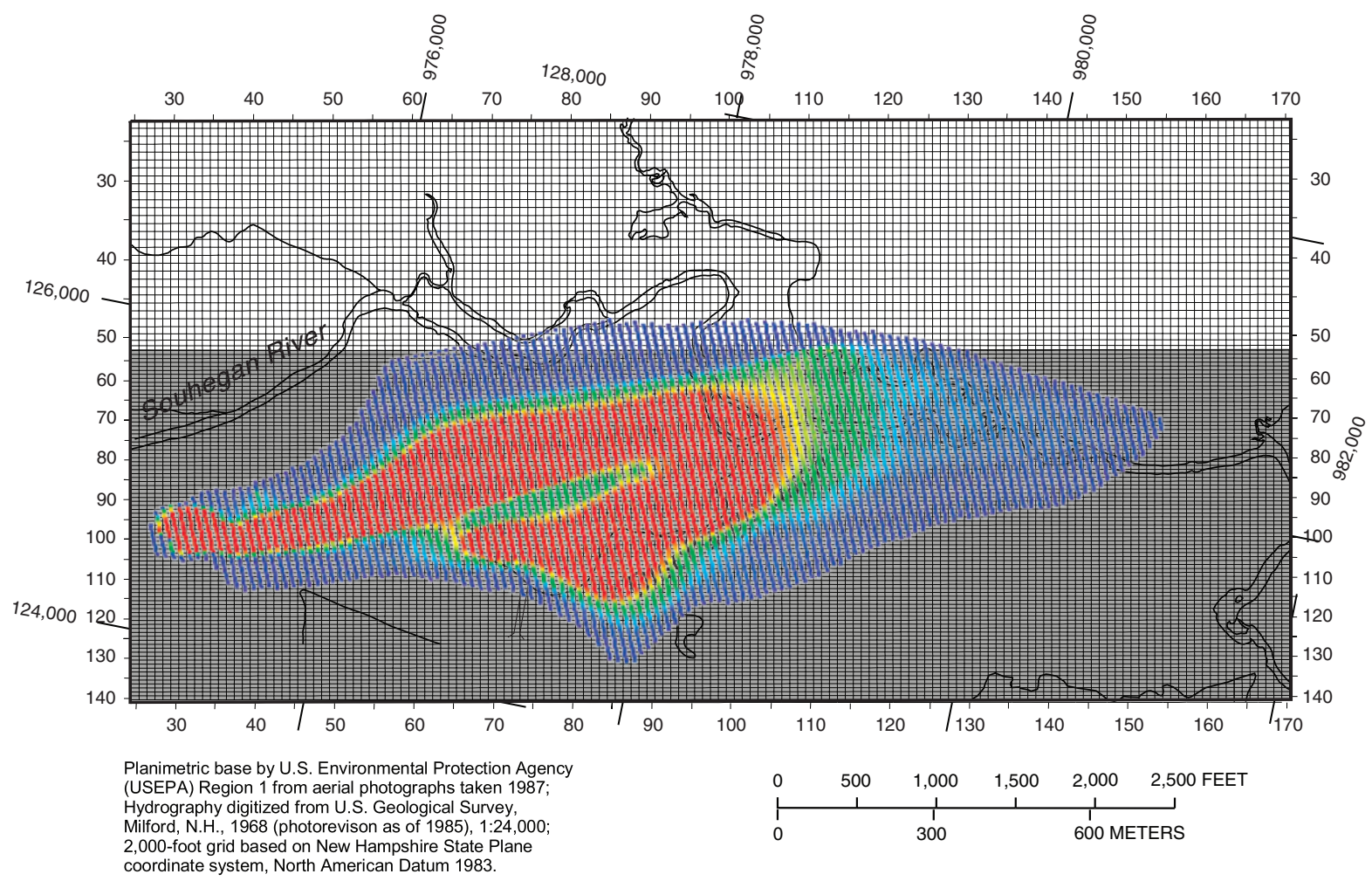

EXPLANATION

PCE concentration,

in parts per billion

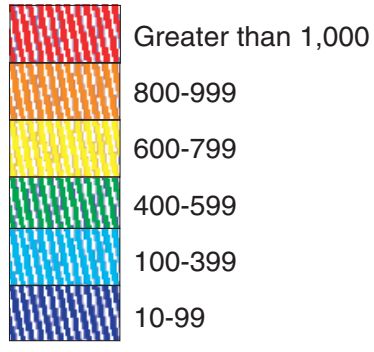

Solute transport subgrids

Pre-remedial simulation

Remedial simulation

Figure 3-2. Subgrid of a steady-state solute-transport model and initial tetrachloroethylene (PCE) concentration from simulated pre-remedial conditions, Savage Superfund site, Milford, N.H. (Modified from Harte, 2004) 


\section{Example test run: Interactive (user defined) designation of zone values for the Savage Steady} State, Solute-Transport model.

1. Input instructions follow (Unbolded font is program prompts and output, bold is user typed response, red is author commentary (not provided in program).

Enter Input CNCA FILE NAME:

rbw100e.cna

INPUT NAME IS: rbw100e.cna

ENTER OUTPUT FILE NAME 1:

savage-ss 23

ENTER INPUT MOC FILE NAME:

rbw89e.moc

INPUT NAME IS: rbw89e.moc

$4 \quad 52314025170$

SUBGRID ROWS $=118$, SUBGRID COLUMNS $=146$

SUBGRID LAYERS $=5$

INPUT DISCRETIZATION FILE NAME:

rbw90i2k.dis

INPUT NAME IS: rbw90i2k.dis

MODEL LAYERS $=5$ ROWS $=175$ COLS $=189$

ENTER OUTPUT FILE TO WRITE CONC. ARRAY:

check-savss 23

Enter the name of your ZONE INPUT FILE $<\mathrm{cr}=$ interactive:

$<$ cr>

Enter the start layer, stop layer $<0,0$ means done $>$ :

1,5

Enter the start row, stop row:

1,175

Enter the start column, stop column:

1,189

Enter the zone for this block, must no. incremental:

1

Enter the start layer, stop layer $<0,0$ means done $>$ :

$\mathbf{0 , 0}$

This response means stop. Therefore, only one zone is created.

TIME $=0.0000, \#$ of Headers read 1

TIME $=0.1105 \mathrm{E}+09, \#$ of Headers read 2

Concentration headers read in the CNCA file are displayed here. The CNCA file prints a header for each time period and layer (only 1 in this case).

$98065=$ Number of Active Cells counted

The number of non-negative concentration values in the CNCA file are displayed here. The concentration array size can be checked by dividing the number of active cells by the number of headers. In this example, 49,032 cells out of a maximum subgrid size of 86,140 cells for a 5 layer by 118 rows by 146 columns. The maximum cell size $(86,140)$ exceeds the 49,032 cells because the number of active cells decreases in the lower layers (2-4) because of the shape of the valley.

Program Completed

Press Enter to Continue.

$<$ CR $>$ 
2. Output example from the main output file.

ZONECONC VERSION 1.50

SUMMARY STATS PER LAYER AND ZONE, RUN = rbw100e.cna

OUTPUT FILE NAME $=$ sav-ss23

Zone block: LAYERS 1- 1 ROWS 1-175 COLUMNS 1-189 VALUE: 1

Zone block: LAYERS 2- 2 ROWS 1-175 COLUMNS 1-189 VALUE: 2

Zone block: LAYERS 3- 3 ROWS 1-175 COLUMNS 1-189 VALUE: 3

Zone block: LAYERS 4- 4 ROWS 1-175 COLUMNS 1-189 VALUE: 4

Zone block: LAYERS 5- 5 ROWS 1-175 COLUMNS 1-189 VALUE: 5

NUMBER OF ZONES: 5

READING CONCENTRATION DATA

STATISTICS ARE CALCULATED ON NON-NEGATIVE (VALUES $=>0$ ) CONCENTRATION EXCEPT PCOUNT $($ VALUES $>0$ )

$\begin{array}{lcllccllllll}\text { TIME } & \text { ZONE } & \text { MAX. } & \text { ROW } & \text { COL. } & \text { LAYER } & \text { MIN. } & \text { MEAN } & \text { TOTAL } & \text { COUNT } & \text { PCOUNT } & \text { STAND. DEV. } \\ 0.00000 & 1 & 0.7244 \mathrm{E}+04 & 90 & 27 & 1 & 0.0000 \mathrm{E}+00 & 0.7127 \mathrm{E}+02 & 0.1098 \mathrm{E}+07 & 15400 & 8626 & 0.1839 \mathrm{E}+03 \\ 0.00000 & 2 & 0.8875 \mathrm{E}+04 & 89 & 32 & 2 & 0.0000 \mathrm{E}+00 & 0.1688 \mathrm{E}+03 & 0.2468 \mathrm{E}+07 & 14623 & 8589 & 0.3597 \mathrm{E}+03 \\ 0.00000 & 3 & 0.5279 \mathrm{E}+04 & 87 & 32 & 3 & 0.0000 \mathrm{E}+00 & 0.3037 \mathrm{E}+03 & 0.3668 \mathrm{E}+07 & 12077 & 7946 & 0.5279 \mathrm{E}+03 \\ 0.00000 & 4 & 0.5097 \mathrm{E}+04 & 86 & 32 & 4 & 0.0000 \mathrm{E}+00 & 0.4123 \mathrm{E}+03 & 0.2222 \mathrm{E}+07 & 5388 & 3459 & 0.7703 \mathrm{E}+03 \\ 0.00000 & 5 & 0.5097 \mathrm{E}+04 & 86 & 32 & 5 & 0.1000 \mathrm{E}+02 & 0.7189 \mathrm{E}+03 & 0.1428 \mathrm{E}+07 & 1986 & 1986 & 0.9604 \mathrm{E}+03 \\ 0.110450 \mathrm{E}+09 & 1 & 0.9534 \mathrm{E}+03 & 67 & 98 & 1 & 0.1983 \mathrm{E}-12 & 0.1115 \mathrm{E}+03 & 0.1689 \mathrm{E}+07 & 15146 & 15146 & 0.2025 \mathrm{E}+03 \\ 0.110450 \mathrm{E}+09 & 2 & 0.1205 \mathrm{E}+04 & 82 & 59 & 2 & 0.7147 \mathrm{E}-12 & 0.1498 \mathrm{E}+03 & 0.2130 \mathrm{E}+07 & 14217 & 14217 & 0.2551 \mathrm{E}+03 \\ 0.110450 \mathrm{E}+09 & 3 & 0.1391 \mathrm{E}+04 & 83 & 58 & 3 & 0.1317 \mathrm{E}-11 & 0.1966 \mathrm{E}+03 & 0.2364 \mathrm{E}+07 & 12022 & 12022 & 0.3025 \mathrm{E}+03 \\ 0.110450 \mathrm{E}+09 & 4 & 0.1709 \mathrm{E}+04 & 84 & 57 & 4 & 0.2249 \mathrm{E}-12 & 0.2558 \mathrm{E}+03 & 0.1335 \mathrm{E}+07 & 5220 & 5220 & 0.4049 \mathrm{E}+03 \\ 0.110450 \mathrm{E}+09 & 5 & 0.2739 \mathrm{E}+04 & 87 & 35 & 5 & 0.8587 \mathrm{E}+00 & 0.5146 \mathrm{E}+03 & 0.1022 \mathrm{E}+07 & 1986 & 1986 & 0.6100 \mathrm{E}+03\end{array}$

Examination of this example shows the maximum concentration and the total concentration decrease with time. The maximum concentration location occurs at around column 32 in all 5 layers for the intial time. The maximum concentration occurs in layer 2 but the total concentration is greatest in layer 3. The initial time shows 15,400 (COUNT) cells are non-negative with 8,626 (PCOUNT) positive cells in layer 1. The number of non-negative and positive cells decrease from layer 1 to layer 5 . The maximum concentration at any cell decreases by approximately 80 percent for the final time in layers $1-2$, and by approximately 66 percent for layers 3-5. This result indicates attenuation of the solute is lowest for layers $3-5$. Whereas the maximum concentration at any cell decreases between 80 and 66 percent, the total concentration shows an overall smaller decrease (about 50 percent). Therefore, part of the change in maximum concentration is due to dispersion and redistribution of contaminants within the aquifer because the total concentration decreased less than the maximum concentration. This redistribution is supported by an increase in the number of positive concentration cells (PCOUNT) with time, which indicates a spreading of the solute between the initial and final time. 
Prepared by the New Hampshire-Vermont Water Science Center Publications Unit

For more information concerning the research in this report, contact:

Keith W. Robinson, Acting Director

U.S. Geological Survey

New Hampshire-Vermont Water Science Center

361 Commerce Way

Pembroke, NH 03275

or visit our Web site at:

http://nh.water.usgs.gov 

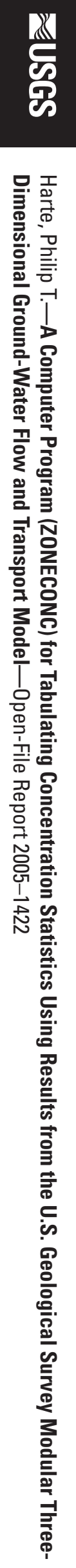